\title{
Modulation of Local and Systemic Heterocellular Communication by Mechanical Forces: A Role of Endothelial Nitric Oxide Synthase
}

\author{
Ralf Erkens, Tatsiana Suvorava, Christian M. Kramer, Lukas D. Diederich, \\ Malte Kelm, and Miriam M. Cortese-Krott
}

\begin{abstract}
Significance: In this review, we discuss the role of nitric oxide (NO) as a key physiological mechanotransducer modulating both local and systemic heterocellular communication and contributing to the integrated (patho)physiology of the cardiovascular system. A deeper understanding of mechanotransduction-mediated local and systemic nodes controlling heterocellular communication between the endothelium, blood cells, and other cell types (e.g., cardiomyocytes) may suggest novel therapeutic strategies for endothelial dysfunction and cardiovascular disease.

Recent Advances: Mechanical forces acting on mechanoreceptors on endothelial cells activate the endothelial NO synthase (eNOS) to produce NO. NO participates in (i) abluminal heterocellular communication, inducing vasorelaxation, and thereby regulating vascular tone and blood pressure; (ii) luminal heterocellular communication, inhibiting platelet aggregation, and controlling hemostasis; and (iii) systemic heterocellular communication, contributing to adaptive physiological processes in response to exercise and remote ischemic preconditioning. Interestingly, shear-induced eNOS-dependent activation of vascular heterocellular communication constitutes the molecular basis of all methods applied in the clinical routine for evaluation of endothelial function.

Critical Issues and Future Directions: The integrated physiology of heterocellular communication is still not fully understood. Dedicated experimental models are needed to analyze messengers and mechanisms underpinning heterocellular communication in response to physical forces in the cardiovascular system (and elsewhere). Antioxid. Redox Signal. 26, 917-935.
\end{abstract}

Keywords: shear stress, nitric oxide, red blood cells, red cell eNOS, endothelial dysfunction, mechanobiology

\section{Introduction}

$\mathbf{N}_{\mathrm{a}}^{\mathrm{n}}$ ITRIC OXIDE (NO) is one of the evolutionary, oldest (46), and best characterized messengers, playing a key role in local and systemic heterocellular communication. In the cardiovascular system, NO is constitutively produced within the endothelium from the enzymatic conversion of $\mathrm{L}$ - arginine into L-citrulline by the type 3 isoform of the nitric oxide synthase (NOS3), also defined as endothelial NOS (eNOS; EC 1.14.13.39), according to the first tissues from where it was isolated $(63,104,128)$.

NO carries physicochemical characteristics, making it an ideal messenger for transferring physiological signals within cells, through cells, and among tissues. Compared with other

Cardiovascular Research Laboratory, Division of Cardiology, Pneumology and Angiology, Medical Faculty, Heinrich Heine University of Düsseldorf, Düsseldorf, Germany.

(C) Ralf Erkens, et al. 2017; Published by Mary Ann Liebert, Inc. This is an Open Access article distributed under the terms of the Creative Commons Attribution License, which permits unrestricted use, distribution, and reproduction in any medium, provided the original work is properly cited. Mary Ann Liebert, Inc. offers reprint services for those who want to order professionally produced copies of articles published under the Creative Commons Attribution (CC BY) license. To obtain a price quote, email Reprints@liebertpub.com. Please include the article's title or DOI, quantity, and delivery destination in your email. 
free radicals participating in redox signaling, for example, superoxide radical anion $\left(\mathrm{O}_{2}^{-\bullet}\right)$, NO is more stable and less reactive toward biologically relevant thiols, ${ }^{\text {a }}$ such as cysteine and glutathione (53), which are found in millimolar concentrations in cells and tissues. Its peculiar reactivity, together with its lack of charge, allows NO to survive the reducing thiol-rich environment of the cell, to cross cell membranes, and to reach its molecular targets outside in the subluminal and luminal side of the vascular endothelium (Fig. 1). NO has a high affinity for $\mathrm{Fe}^{2+}$-heme centers and rapidly reacts with the soluble guanylate cyclase (sGC; EC 4.6.1.2); sGC catalyzes the conversion of guanosine- $5^{\prime}$ triphosphate (GTP) into the second messenger $3^{\prime}, 5^{\prime}$-cyclic guanosine monophosphate (cGMP), which in turn activates its downstream signaling cascade $(8,32)$. Although the chemical biology of NO-mediated S-nitrosation of biological thiols is still a matter of debate $(27,69)$, S-nitrosothiols are found in low $\mu M$ concentrations in vascular tissues, with higher concentrations in rodents than humans $(17,47,116,120)$. In addition, NO may exert pleiotropic cGMP-independent effects via S-nitrosation of key cysteines in enzymes and proteins modifying their activity (6).

In the endothelium, eNOS activity is tightly regulated by different mechanisms, including (i) localization of the enzyme (85, 129); (ii) availability of the substrate L-arginine, of cofactors such as tetrahydrobiopterin, and $\mathrm{Ca}^{2+} /$ calmodulin (CaM), which are all essential for NOS activity (63); (iii) phosphorylation at specific amino acids, which may lead to both activation or inhibition of eNOS activity depending on their localization in the protein sequence, as well as on the phosphorylation map (40, 48, 50); (iv) other post-transcriptional modifications, such as S-nitrosation $(45,118)$, glutathionylation (23), and persulfidation (5), which were shown to modify eNOS activity; and (v) transcriptional and post-transcriptional regulation, including changes of gene expression, messenger RNA (mRNA) stability, or microRNA (miRNA)-dependent mRNA degradation, as extensively revised by Balligand et al. (10).

In addition to the well-known receptor-mediated activation of eNOS, for example, by agonists such as acetylcholine (ACh) or bradykinin (BK) (141), mechanical forces are among the most important physiological regulators of eNOSdependent NO production in the endothelium $(10,11,21,83)$, and multiple pathways of eNOS activation are involved. The vascular endothelium is exposed to pulsatile flow, conjugating in a temporally defined manner both tangential and circumferential mechanical forces $(10,21,35,83)$. Tangential forces (also defined as shear stress) have been shown to activate tightly regulated biochemical responses by activation of membrane or cytoskeletal proteins (defined as mechanosensors), leading to the activation of biochemical pathways, thus transforming mechanical stimulation into biochemical signal transduction (a process defined as mechanotransduction), which elicits highly regulated physiological responses.

Endothelial NO-mediated mechanosensing and mechanotransduction are mainly considered as local processes.

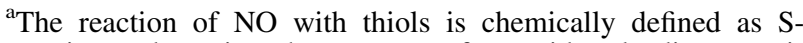
nitrosation and requires the presence of an oxidant leading to oxidation of $\mathrm{NO}$ to a nitrosating species (such as $\mathrm{N}_{2} \mathrm{O}_{3}$ or $\mathrm{NO}_{2}$ ) or of the thiol to thiyl radical, allowing a radical-radical reaction. Although nitrosothiols are found in low $\mu M$ concentrations in biological tissues (47), the mechanisms underlining S-nitrosation reaction in cells and tissues are still under discussion.
}

However, it is well known that eNOS-derived NO may exert paracrine effects also via formation of bioactive circulating metabolites $(17,47,120)$, including nitrite $(31,38,61,101$, $117,137)$, and thereby participates in systemic heterocellular communication (Fig. 1).

In this review, we aim to discuss the role of $\mathrm{NO}$ as a main mechanotransduction messenger in local and systemic heterocellular communication. We will review the role of NO in (i) abluminal heterocellular communication induced by mechanical forces, that is, the mechanisms of mechanosensing and mechanotransduction in the endothelium focusing on flow-mediated eNOS activation, NO production, and vasodilation; (ii) luminal heterocellular communication, that is, the NO-mediated communication among endothelial cells and blood cells; and (iii) systemic heterocellular communication induced by physical forces, that is, the role of NOmediated mechanotransduction in remote communication involved in organ protection. Moreover, we will discuss (iv) the clinical implication of shear stress-induced eNOSmediated heterocellular communication (Fig. 1). A deeper understanding of mechanotransduction-mediated local and systemic nodes controlling heterocellular communication between the endothelium and other cell types may provide novel therapeutic strategies to be applied in conditions associated with endothelial dysfunction and cardiovascular disease.

\section{Abluminal Heterocellular Communication Induced by Mechanical Forces}

Endothelial cells sense changes in local hemodynamic patterns by the presence of mechanoreceptors localized on their membrane (respectively, on the luminal side of the membrane, in junctional complexes connecting two adjacent cells, or in focal adhesions in the subluminal side of the membrane of cells) as well as inside the cells (i.e., the cytoskeleton). The endothelial cells respond to the mechanical signal by activation of biochemical pathways (= mechanotransduction), which lead to physiological effects, including changes in arterial wall vasomotion, structure, and gene expression profile. In the following section, we will focus on the shear-induced signaling pathways activating eNOS-derived NO formation and heterocellular signaling between endothelial cells and smooth muscle cells (SMCs), thereby regulating vascular tone and blood pressure.

\section{Shear-dependent vasodilatory response}

Shear-mediated activation of eNOS activity occurs mainly via three major mechanisms, which are depicted in Figure 2. Activation of mechanosensors can lead (i) to mobilization of intracellular $\mathrm{Ca}^{2+}$ stores, to an increase in intracellular $\mathrm{Ca}^{2+}$ concentration $\left(\left[\mathrm{Ca}^{2+}\right]_{\mathrm{i}}\right)$, and to formation of $\mathrm{Ca}^{2+} / \mathrm{CaM}$ complexes, which activate eNOS by binding to a short regulatory sequence between the two subunits of eNOS (18); (ii) to activation of shear-sensitive protein kinases, phosphorylation of eNOS at specific amino acids, leading to activation or inhibition of the enzyme depending on the phosphorylation site and on the phosphorylation map (50); and (iii) to regulation of expression levels of eNOS, which is mediated by the activation of transcription factors, including activator protein 1 (AP-1), nuclear factor kappa-light-chain-enhancer of activated $\mathrm{B}$ cells $(\mathrm{NF}-\mathrm{kB})$, early growth response protein 1 (Egr-1), 


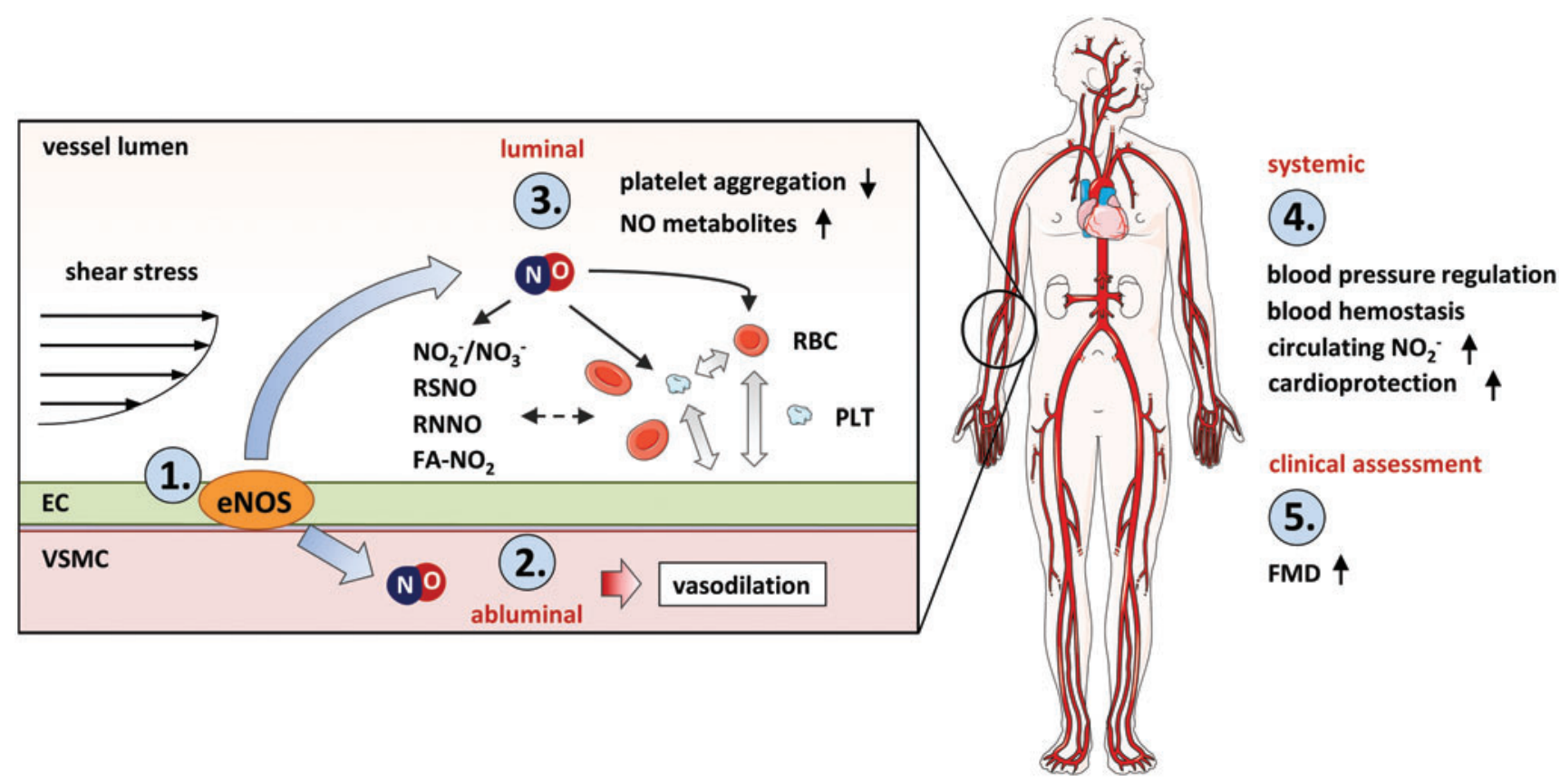

FIG. 1. The role of NO as a key mechanotransduction messenger in local and systemic heterocellular communication. (1) Shear stress acts on mechanoreceptors on the endothelium and activates eNOS in endothelial cells to produce NO. (2) NO participates in abluminal heterocellular communication, inducing vasodilation and thereby regulation of vascular tone and blood pressure. (3) NO participates in luminal heterocellular communication among endothelial cells, platelets, and RBCs leading, for example, to inhibition of platelet aggregation (4) NO and its metabolites contribute to systemic heterocellular communication and participate in complex physiological processes induced by changes in mechanical forces, which lead to organ protection; examples are the effects of exercise training and remote ischemic preconditioning. (5.) In clinical and experimental settings, endothelial function is assessed as FMD. This technique is mainly based on shear stress-dependent activation of eNOS-mediated vasodilation (although other vasodilators/vasoconstrictors are involved as well). FMD, flow-mediated dilation; RBC, red blood cell. To see this illustration in color, the reader is referred to the web version of this article at www.liebertpub.com/ars

specificity protein 1 (SP-1), GATA-binding protein 6 (GATA6), and Krüppel-like factor 2 (KLF2) (97). In addition, the expression of eNOS is tightly regulated by posttranslational mechanisms, including mRNA stability and miRNA-dependent regulation (10). These signaling pathways are deeply intertwined and may act simultaneously and ensure short- and long-term eNOS regulation.

Experimental studies have shown that shear stress affects NO production and heterocellular communication by eNOS in two phases. On applying shear stress, there is a first brief transient $\mathrm{Ca}^{2+} \mathrm{CaM}$-dependent NO burst, which is responsible for short-term activation of eNOS, whereas activation of phosphorylation cascades controls eNOS activity to assure sustained and moderate NO generation (50). NO produced by the endothelium is then released into the subluminal space and reaches the SMC, where NO binds reversibly to the prosthetic ferrous heme group $\left(\mathrm{Fe}^{2+}\right)$ of the sGC with complex binding kinetics (150), resulting in a conformational change that activates the enzyme. The sGC is a heterodimer, consisting of an $\alpha$ - and a $\beta$-subunit, but only the latter contains the prosthetic group (149), and exists in two isoforms both expressed in the vasculature $(102,123)$. The enzyme catalyzes the conversion of GTP to cGMP, which in turn activates cGMP-dependent protein kinases (PKG) and other targets (115). In vascular SMCs (VSMCs), activation of PKG induces vasorelaxation by multiple mechanisms, including (i) phosphorylation of phospholamban, and sarcoendoplasmic reticulum calcium trans- port ATPase (SERCA)-dependent decrease in intracellular $\mathrm{Ca}^{2+}$ concentrations; (ii) phosphorylation of IRAG, decrease in $\mathrm{IP}_{3}$, and decrease in intracellular $\mathrm{Ca}^{2+}$ concentrations; or (iii) changes in activity of $\mathrm{K}^{+}$channels, causing membrane hyperpolarization, inhibition of extracellular $\mathrm{Ca}^{2+}$ influx, and decrease in intracellular $\mathrm{Ca}^{+2}$ concentration, as well as phosphorylation of myosin light chain kinase, which then results in dephosphorylation of myosin light chains (which is also dependent on the activity of a myosin light chain phosphatase), leading to smooth muscle relaxation. Taken together, shear stress keeps eNOS-derived NO production constant, thereby regulating vascular diameter and tone.

Resistance vessels are the main target for peripheral mechanisms controlling blood pressure. Isakson and coworkers (133) discovered that NO-mediated heterocellular communication between endothelium and SMCs in resistance vessels is fine-tuned by the redox state of hemoglobin $\alpha$ within myoendothelial junctions (membrane structures connecting endothelium with SMCs). Thus, if the iron heme of hemoglobin $\alpha$ is oxidized $\left(\mathrm{Fe}^{3+}\right)$, NO can diffuse through the myoendothelial junction and reach the SMC; however, if the iron heme of hemoglobin $\alpha$ is reduced $\left(\mathrm{Fe}^{2+}\right)$, NO will bind to hemoglobin $\alpha$ and this will prevent diffusion of NO in the SMC. Regulation of the oxidative state of hemoglobin $\alpha$ is attributed to the enzyme CYB5R3 (133). This work was a new milestone in understanding eNOS-dependent blood pressure regulation involving hemoglobin $\alpha$; this new role of 


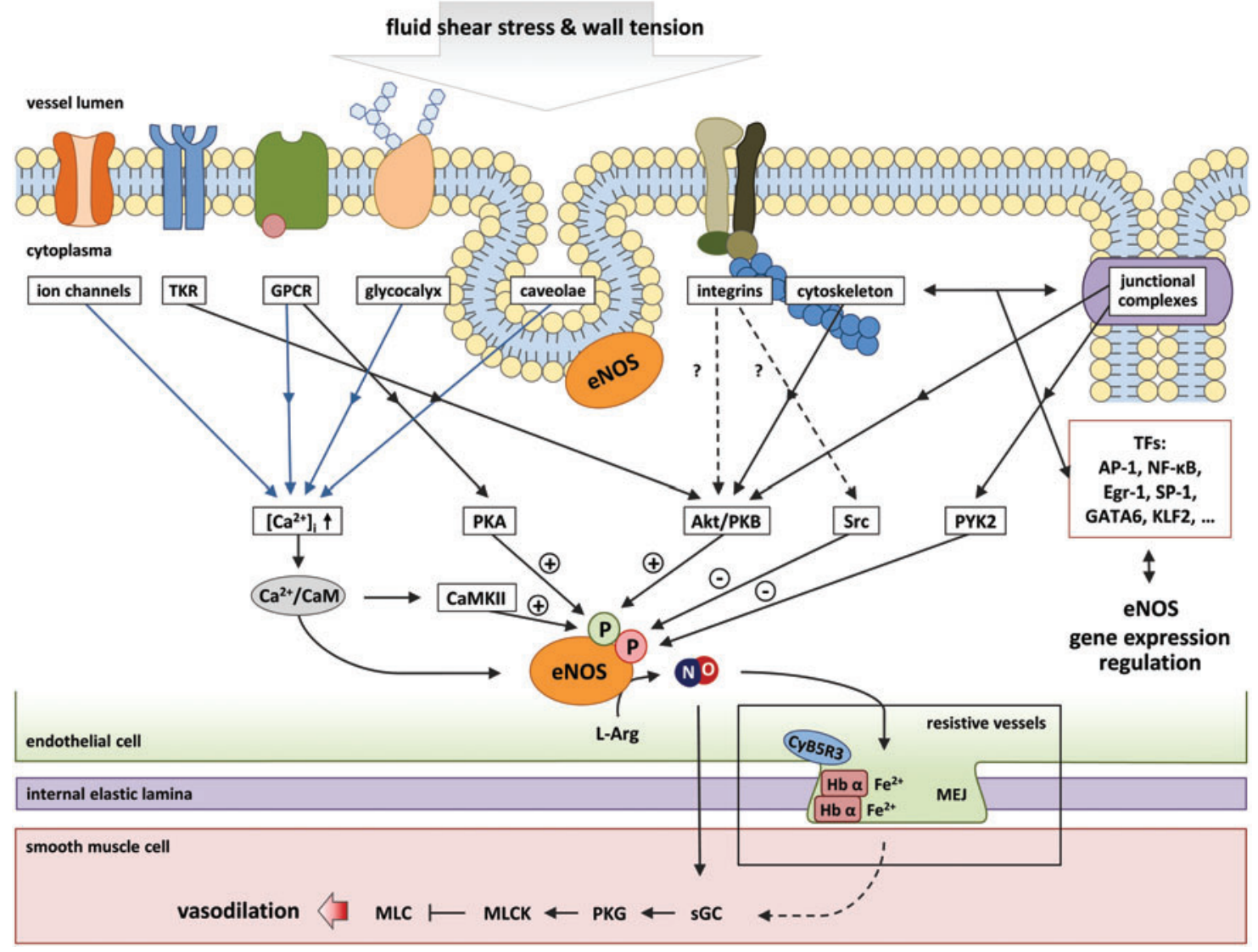

FIG. 2. Mechanisms of endothelial mechanosensing leading to eNOS activation and local heterocellular signaling in the vascular wall. Endothelial mechanosensors can be found respectively on the luminal side of the membrane, in junctional complexes connecting two adjacent cells, or in focal adhesions in the subluminal side of the membrane of cells or inside cells (such as the cytoskeleton or cytoplasmic TK). The activation of mechanosensors leads to short-term regulation of eNOS by increase in intracellular $\mathrm{Ca}^{2+}$ concentration and/or by activation of protein kinases, which may lead to both activation and inhibition of eNOS activity. These mechanisms may initiate long-term transcriptional regulation by activation of transcription factors (or other transcriptional mechanisms). NO can freely diffuse into the smooth muscle cells, activate sGC, and induce vasodilation. In resistance vessels, NO diffusion is tightly controlled in the myoendothelial junction by the redox state of hemoglobin $\alpha$. AP-1, activator protein 1; CaM, calmodulin; CaMKII, calcium/calmodulindependent protein kinase II; Egr-1, early growth response protein 1; eNOS, endothelial nitric oxide synthase; GATA6, GATA-binding protein 6 ; $\mathrm{Hb} \alpha$, hemoglobin $\alpha$; KLF2, Krüppel-like factor 2; L-Arg, L-arginine; MEJ, myoendothelial junction; MLC, myosin light chain; MLCK, myosin light chain kinase; NO, nitric oxide; NF-kB, nuclear factor kappa-lightchain-enhancer of activated B cells; PYK2, proline-rich tyrosine kinase 2; PKA, protein kinase A; PKB, protein kinase B; PKG, protein kinase G; sGC, soluble guanylate cyclase; SP-1, specificity protein 1; TF, transcriptional factor; TK, tyrosine kinase. To see this illustration in color, the reader is referred to the web version of this article at www.liebertpub.com/ars

hemoglobin $\alpha$ within the vascular wall as a direct regulator of NO-mediated control of vascular tone and blood pressure is independent from the role of hemoglobin $(\alpha \beta)$ within the red blood cell (RBC), which is known to act as scavenger, transporter, and producer of NO, (discussed in the section "NO-Mediated Luminal Heterocellular Communication: Endothelium, Platelets, and RBCs").

\section{Mechanisms of endothelial mechanosensing}

Accumulating evidence indicates that the vascular endothelium, SMCs, and other cell types, including RBCs and platelets $(113,143)$, are well equipped with proteins responsible for mechanosensing and mechanotransduction, able to sense shear stress, stretch, and other mechanical stimulations.
Mechanosensors involved in eNOS activation can be found on cell surface, respectively, (i) membrane structures controlling eNOS localization (caveolae), (ii) on the luminal side of the membrane, including the glycocalyx, ion channels, and G protein-coupled receptors (GPCRs) (such as the BK-2 receptor); (iii) in junctional complexes connecting two adjacent cells, including the vascular endothelial growth factor receptor 2 (VGEFR2)/platelet endothelial cell adhesion molecule-1 (PECAM-1) complex; (iv) in focal adhesions in the subluminal side of the membrane of the cells, including integrins (such as $\alpha 1 \beta 1$ ), or (v) inside cells such as the cytoskeleton and intracellular tyrosine kinases (Fig. 2). These are responsible for cells and force specific stimulation and cellular response (Fig. 2). These pathways are studied in the emerging field of mechanobiology (6). Shear stressdependent stimulation of these receptors leads to the 
activation of complex, partially interdependent downstream signaling pathways (Fig. 2). In this study, we focus on the mechanosensors, which are likely responsible for eNOS activation in the endothelium mainly by two mechanisms (i) increases in $\left[\mathrm{Ca}^{+2}\right]_{\mathrm{i}}$ or (ii) activation of phosphorylation cascades leading to regulation of eNOS activity.

Caveolae. Caveolae are flask-shaped invaginations of the membrane with a length of 50-100 nm stabilized by the presence of caveolin-1 and play a central role in regulation of cell membrane organization and signaling (97). Sessa and coworkers demonstrated that caveolae regulate eNOS activity in response to shear stress (159). Caveolin-1 is known to directly interact with the eNOS oxygenase domain and inhibit enzyme activity. Shear stress promotes formation of $\mathrm{Ca}^{2+} / \mathrm{CaM}$ complexes, which bind to eNOS and promote eNOS dissociation from caveolin-1, and eNOS activation (85). Mice, deficient of caveolin-1, have impaired shear stress-dependent regulation of their vessel diameter (159). This impairment was completely reversed by endothelialspecific reexpression of caveolin-1 (159).

Glycocalyx. The glycocalyx is a layer of proteoglycans and glycoproteins on the luminal surface of endothelial cells (119). The glycocalyx has the ability to change its structural conformation in response to flow changes, therefore is an excellent mechanosensor. Since it is directly connected to the cytoskeleton, it enables transduction of the mechanical signal from the outside into the cytoplasm; the mechanical signal can then be redistributed through the cell, influencing other mechanosensors, including intercellular junctions, the luminal surface of cells, abluminal focal adhesion sites, and the nuclear membrane (34). An interesting publication showed that partial degradation of the endothelial cell glycocalyx leads to an impairment of NO production (132). A possible explanation for this phenomenon is that hyaluronic acid, one main constituent of the glycocalyx, is part of a cascade activating $\mathrm{Ca}^{2+}$ influx by interaction with the CD44v10/ caveolin complex. $\mathrm{Ca}^{2+}$ influx may on turn activate $\mathrm{NO}$ production and affect cell adhesion and proliferation (132). Accordingly, it has been shown that the glycocalyx modulates the motility and proliferative response of endothelial cells (157). Since eNOS-derived NO is known to play a central role in endothelial cell proliferation, arteriogenesis, and vasculogenesis, a part of these effects may be dependent on glycocalyx-dependent eNOS activation.

Ion channels. Shear-sensitive ion channels discovered so far are potassium, chloride, and calcium-permeable channels $(76,107)$. With the onset of shear stress, transient receptor potential vanilloid 4 (TRPV4) channels open and allow $\mathrm{Ca}^{2+}$ influx into the endothelial cell, leading to the $\mathrm{Ca}^{2+/} \mathrm{CaM}$ mediated activation of eNOS. By this signal, calcium-activated potassium channels $\left(\mathrm{K}_{\mathrm{Ca}}\right)$ open and release $\mathrm{K}^{+}$leading to cell membrane hyperpolarization. Likewise, hyperpolarization is increased by activation of shear-sensitive inward-rectifying potassium channels $\left(\mathrm{K}_{\mathrm{ir}}\right)$ (106). Hyperpolarization of the membrane activates hyperpolarization-sensitive $\mathrm{Ca}^{2+}$ channels and $\mathrm{Cl}^{-}$ion channels in a time-dependent manner and results in membrane potential depolarization occurring 35-160s after onset of shear stress $(95,114)$.
The mechanism on how blood flow activates these ion channels is yet not fully understood. Three different theories were recently proposed (83). One possible explanation is that ion channels are pushed open due to the drag force. Second, mechanical forces may change the tensional interactions among cytoskeletal proteins (see also the section "the $\mathrm{Cy}$ toskeleton") pulling the channels anchored to the cytoskeleton to open. Third, mechanical forces may affect membrane fluidity by influencing the viscosity of the lipid bilayer. Most likely, it is a combination of these mechanisms that activates ion channels in response to shear stress. An indirect regulation of eNOS activation by mechanosensing channels may also involve shear-dependent activation of ATP release from endothelial cells, leading to activation of the purinergic $\mathrm{P}_{2} \mathrm{X}_{4}$ channel (154). $\mathrm{P} 2 \mathrm{X}_{4}$ triggers $\mathrm{Ca}^{2+}$ influx, increases in intracellular $\mathrm{Ca}^{2+}$ concentration, and activates eNOS. The mechanism responsible for ATP release is still unclear (99).

G protein-coupled receptors. Activation of GPCRs by shear stress was demonstrated for the first time by liposomes carrying isolated GPCRs (64). BK is one of the oldest agonists known to regulate eNOS activity in the endothelium. The classical pathway is characterized by binding of BK to its receptors, activation of protein kinase $\mathrm{C}$, and increase in $\left[\mathrm{Ca}^{2+}\right]_{\mathrm{i}}$ in endothelial cells (20). It was shown that shear stress-dependent activation of BK 2 receptor (B2) results in changes of eNOS activity independent from the presence of BK (84). Under physiological unstressed conditions, the B2 receptor and eNOS form a complex, hindering NO synthesis by eNOS (84). Activation of the $\mathrm{B} 2$ receptor leads to dissociation of eNOS from the endothelial $\mathrm{B} 2$ receptor, making eNOS available for NO synthesis.

A further GPCR activated by shear stress is the purinergic receptor $P 2 Y_{2}$. After activation, this $G_{q} / G_{11}$-linked receptor initiates a signal cascade involving the phosphorylation of PECAM-1, VEGFR2, Src-kinase, and Akt, leading to phosphorylation of eNOS at Ser-1177 (154).

Several possible mechanisms of GPCR-mediated shearinduced changes of membrane bilayer are discussed (20). Simulations of the lipid bilayer suggest that changes in intrabilayer pressures may activate membrane proteins (65). One further mechanism proposed is the change in bilayer thickness and thus improved stabilization of the activated receptor conformation (92).

Junctional complex proteins (VEGFR2/PECAM-1/VEcadherin). A mechanosensitive complex consisting of VEGFR2, PECAM-1, and the adaptor protein VE-cadherin forms junctional complexes between two adjacent cells. These have multiple functional and regulatory properties, playing a role in endothelial permeability and structure (21). The VEGFR2 has been shown to be activated by shear stress independently of the presence of its ligand VEGF (81) and leads to activation of phosphoinositide 3-kinase $\left(\mathrm{PI}_{3} \mathrm{~K}\right)$, the serine-specific protein kinase Akt, which in turn causes phosphorylation of human eNOS at serine $1177(40,81)$. PECAM-1 has no mechanosensing properties, but plays an important role in the delayed $\mathrm{Ca}^{2+}$-independent eNOS activation in response to shear, which seems to involve Aktdependent phosphorylation of eNOS by serine 1177 , as demonstrated in PECAM-1-deficient mice $(51,139)$. 
Focal adhesions and integrins. Integrins are transmembrane proteins regulating cell-cell and cell-matrix interactions and have been shown to influence endothelial response to shear stress in many studies (127). The $\alpha 1 \beta 1$ integrin binds to collagen and laminin and was involved in shear-dependent regulation of eNOS activity in resistance vessels and the microcirculation via activation of PI3-kinase-Akt eNOS signaling (100). Mice lacking the $\alpha_{1}$ integrin gene showed an impairment in flow-mediated dilation (FMD) of mesenteric resistance arteries (100). A study has shown that $\alpha 1 \beta 1$ integrin is absent in endothelial cells of conduit arteries (37).

Cytoskeleton. In mechanobiology, the cytoskeleton is considered as a network capable of transmitting forces throughout the whole cell and simultaneously adapts to mechanical forces (77). According to the tensegrity model, the cytoskeleton comprises elements resistant to compression and not directly attached to each other, as well as elements under steady tension (77). In response to shear stress, the cytoskeleton reorganizes its structure by clustering cytoskeletal and membrane molecules directly connected to it, such as cadherins and integrins. These proteins transmit mechanical forces throughout the cell from one mechanosensing locus to the other, leading to structural rearrangements of cytoskeleton-associated proteins $(e . g .$, resulting in their activation) as well as functional redistribution of cell organelles (145).

Cytoplasmic tyrosine kinases. Two cytoplasmic tyrosine kinases have been shown to participate in shear stressinduced mechanosensing and regulation of eNOS activity, the c-Src kinase (82), and the focal adhesion protein prolinerich tyrosine kinase 2 (Pyk2) $(48,51)$. The Src-kinase increases eNOS transcription via activation of RAS, MEK1/2, and ERK1/2 pathway, as well as mRNA stability by an unknown mechanism (36). Fleming and coworkers have shown that activation of Pyk2 at Tyr 657 in endothelial cells exposed to shear flow results in the decrease or complete loss of eNOS enzymatic activity $(35,48,51)$. The mechanisms of shear stress-induced Pyk2 activation remain controversial, but several potential mechanisms, including integrin stimulation (50), $\mathrm{Ca}^{2+}$ influx without integrin activation (158), and sheardependent increase in vascular oxidative stress (136), have been suggested. The negative regulation of eNOS activity may not only assume a fundamental role for fine-tuning eNOS activity in healthy vessels, but possibly also participate in the pathophysiology of endothelial dysfunction and atherosclerosis (35).

\section{Summary and outlook: mechanosensing and transduction in the vascular wall}

Taken together, understanding how mechanosensing and mechanotransduction in the endothelium regulate heterocellular signaling in the vascular wall and blood is a challenging task. The complex crosstalk between the different mechanotransduction and cell-cell communication pathways contributes to adapt and fine-tune the physiological responses and keep the human vasculature in a well-balanced state. A systematical analysis of these pathways will help to identify the common control nodes regulating short-term and long- term regulatory mechanisms in the vasculature induced by mechanical forces.

\section{NO-Mediated Luminal Heterocellular Communication: Endothelium, Platelets, and RBCs}

NO-mediated heterocellular communication among endothelium and blood cells plays a central role in maintenance of cardiovascular homeostasis. NO produced by the endothelium can be released into the lumen of the vessels and reach the blood stream, where NO can interact with plasma proteins and cellular blood components, including platelets and RBCs. As a result, NO can participate in short-distance heterocellular communication; as an example, NO produced by the endothelium may activate sGC in platelets and thereby inhibit platelet aggregation (Fig. 3).

In RBCs, plasma, or tissues, NO can be transformed into bioactive metabolites allowing long-distance heterocellular communication. RBCs and platelets are both mechanosensing cells $(113,144)$, and changes in flow conditions strongly affect heterocellular communication among them. Shear stress-mediated RBC deformation was shown to cause ATP release (143). Similar to shear-dependent ATP released from endothelial cells (described in the section "Ion Channels"), ATP released from RBCs may bind to purinergic receptors on the surface of the endothelium and activate eNOS to produce NO (99).

In this paragraph, we will focus on shear-induced NOmediated heterocellular communication in the vascular lumen, particularly (i) on NO-dependent effects on platelet aggregation and hemostasis; (ii) on the role of RBCs in NO metabolism, transport, and production; and (iii) on mechanosensing and mechanotransduction in RBCs and the effects of endogenous and exogenous NO on their mechanoproperties, including RBC deformability.

\section{Platelets, shear, and NO}

Very early, it was observed that endothelium-derived NO inhibits platelet aggregation via activation of the sGC/cGMP/ PKG pathway in platelets (142). Interestingly, platelets carry high levels of sGC, and are characterized by the highest NOstimulated cGMP-forming activity (14) among cells belonging to the cardiovascular system, including vascular cells, cardiomyocytes, and blood cells. The constitutively shear-induced eNOS-derived NO production by the endothelium inhibits platelet aggregation and thereby contributes to the regulation of hemostasis in blood (56).

NO was also shown to inhibit platelet recruitment (142). Recently, a biphasic response to NO in platelets, consisting of a transient stimulatory response inducing platelet aggregation, followed by an inhibitory pathway limiting the size of thrombus formation, was found $(13,160)$. This work was criticized by others, who never found any proaggregation effects of NO (55); instead, these authors presented compelling arguments demonstrating that the NO/sGC/cGMP/ PKG pathway inhibits and does not enhance platelet aggregation $(33,122)$.

The role of shear stress-mediated eNOS activation in hemostasis and inhibition of thrombus formation was confirmed by observations linking low endothelial shear stress with downregulation of eNOS and prostacyclin, and increased thrombogenicity, or by analyzing atherothrombotic events 


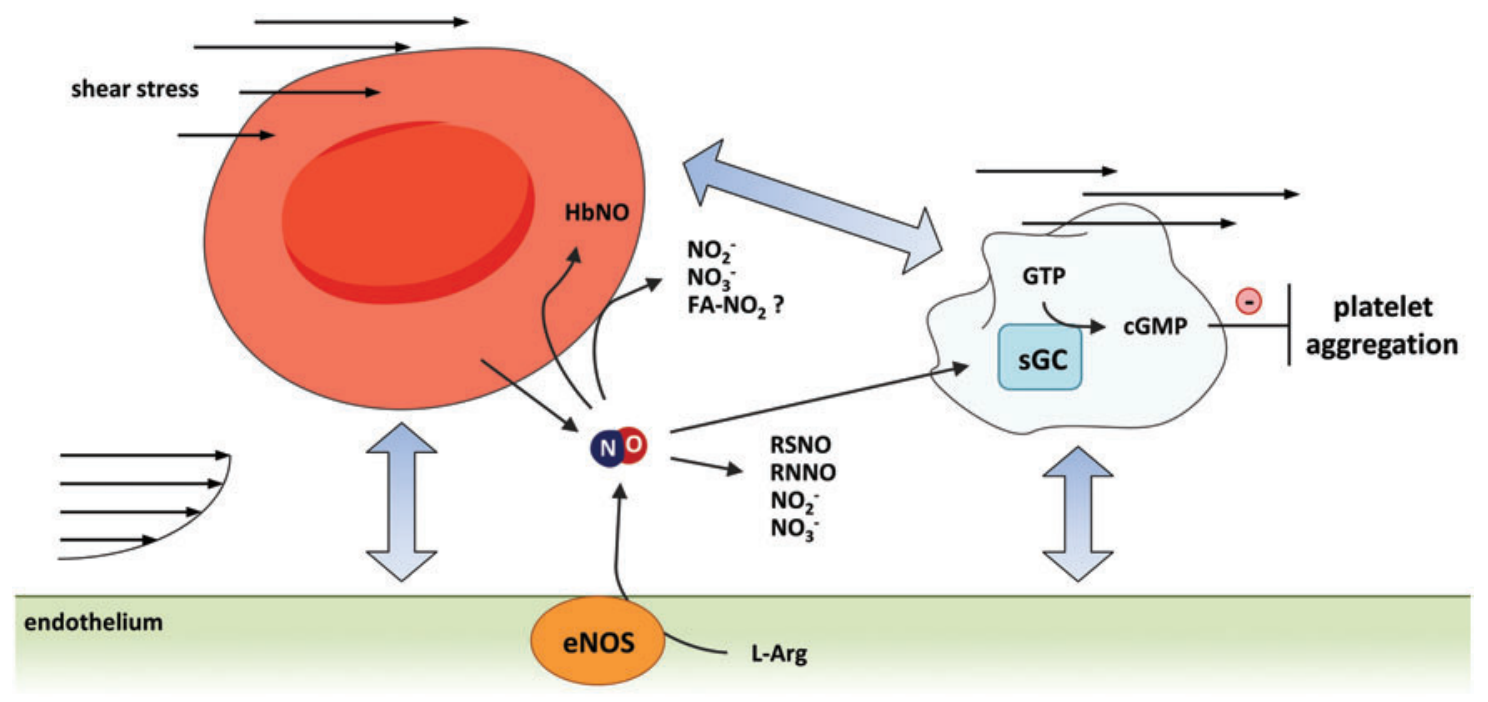

FIG. 3. Luminal heterocellular communication. NO may act also on the luminal site of the endothelium and contribute to luminal heterocellular communication among endothelial cells, platelets, and RBCs. Endothelium-derived NO controls platelet aggregation and hemostasis. In RBCs endothelium-derived NO can be inactivated by the reaction of NO with oxyhemoglobin. In addition, NO can form bioactive metabolites and transform NO into a longer living signal, thus allowing long-distance heterocellular communication and systemic effects. To see this illustration in color, the reader is referred to the web version of this article at www.liebertpub.com/ars

induced after endothelial injury (22). Similar results were shown in ex vivo studies where platelet aggregation was studied in the presence of cultured endothelial cell monolayers in flow chambers (mainly using human umbilical vein endothelial cells) (130).

NO released by the endothelium in response to shear stress is only one of the mechanotransducers involved in heterocellular signaling among platelets, endothelial cells, RBCs, leukocytes, other blood cells, or microparticles. Platelets are themselves mechanosensing cells, able to feel their mechanical microenvironment and dynamically respond to it (113). Aggregation, disaggregation, adhesion, and recruitment of platelets are strongly affected by both the nature of mechanical forces acting on them (i.e., the flow conditions) and by the presence/absence of adhesion molecules and/or soluble biochemical messengers in blood, released by endothelial cells and by blood cells (94, 130).

RBCs and control of NO metabolism, transport, and production

The role of RBCs in NO metabolism is complex and highly debated. RBCs may participate in luminal heterocellular communication by scavenging, transporting, and releasing NO or its metabolites, as described in the following paragraphs.

NO scavenging by RBCs. In the blood stream, endothelial NO is taken up and inactivated by RBCs by an oxidation reaction catalyzed by oxyhemoglobin (oxyHb or $\mathrm{Fe}^{\mathrm{II}} \mathrm{O}_{2} \mathrm{Hb}$ ) producing methemoglobin (metHb or $\mathrm{Fe}^{\mathrm{III}} \mathrm{Hb}$ ) and nitrate according to the following reaction (Eq. 1) (96):

$$
\mathrm{Fe}^{\mathrm{II}} \mathrm{O}_{2} \mathrm{Hb}+\mathrm{NO} \rightarrow \mathrm{Fe}^{\mathrm{III}} \mathrm{Hb}+\mathrm{NO}_{3}^{-}
$$

This reaction is very fast $\left(\approx 10^{7} M^{-1} \mathrm{~s}^{-1}\right)(41,96)$ and converts NO into nitrate, which was thought to be biologically inert. ${ }^{\mathrm{b}}$ Therefore, this reaction was considered to be responsible for inactivation of endothelial NO signaling (28), and RBCs were considered as the major sink for NO in the circulation. Ex vivo experiments could show that the half-life of NO in plasma alone is about $1.5-6 \mathrm{~min}(98)$ and that the addition of RBCs decreases this time to $1.8 \mathrm{~ms}$, which is 1000 times slower than the direct reaction of NO with free hemoglobin. These differences were explained by considering the behavior of RBCs in the flow and observing that particularly in conductance artery the RBCs accumulate in the center of the vessel and create an unstirred layer of plasma, which decrease the diffusion of NO (39).

NO production by RBCs: hypoxic conditions. The observation that under hypoxic conditions, coincubation of RBCs with vascular stripes induced vasodilation (a phenomenon defined as hypoxic vasodilation), which appeared to be dependent on release of NO/NO metabolites from RBCs (109), induced a radical change of view in the field. RBCs were proposed to convert endothelium-derived NO into bioactive metabolites and to release NO on demand under hypoxic conditions when the eNOS activity is impaired. The bioactive NO metabolite acting as NO source in RBCs was proposed to be s-nitrosohemoglobin (HbSNO), produced within the RBCs by the binding of NO to the highly conserved $\beta$-chain Cys-93 residue (80). However, the observation that very low levels of s-nitrosothiols are carried by rodent RBCs (146), and even nondetectable levels in human RBCs (116), induced a radical rethink of the proposed mechanism. Later on, it was

\footnotetext{
${ }^{\mathrm{b}}$ Nitrate was recently shown to participate in biological signaling, also by bioactivation. In fact, there is some evidence of a conversion of nitrate into nitrite by nitrate reductases not only in bacterial flora but also in mammalian tissues as demonstrated by Lundberg et al. (101)
} 
shown that RBCs lacking the hemoglobin Cys-93 amino acid did not negatively affect hypoxic vasodilation (78); however, some evidence of the role of Cys-93 was presented recently (161). More research is needed to define the role of Cys-93 in hypoxic vasodilation.

Interestingly, it was observed that RBCs carry a bulk of nitrite (38) and that there is a significant circulating arterialvenous nitrite gradient (61). Therefore nitrite, and not Snitrosohemoglobin, was proposed to be the substrate of nonenzymatic NO synthesis in RBCs, which is converted into NO by a reaction catalyzed by deoxyhemoglobin $(38,61$, 116, 146). Iron-nitrosylhemoglobin was also proposed to be responsible for NO bioactivity in RBCs (74). Further mechanisms of nitrite bioactivation were proposed to be responsible for the conversion of nitrite into NO. It was proposed that nitrite reduction into NO can be catalyzed by carbonic anhydrase (1) or by xanthine oxidase carried by RBCs and other tissues $(58,148)$ and even by eNOS $(148)$. Recent experiments carried out by electron paramagnetic resonance showed that the activity of deoxyhemoglobin is essential for nitrite-derived NO release from RBCs under hypoxic conditions (96) as treatment of RBCs with carbon monoxide completely blocked nitrite reduction, while inhibition of xanthine oxidase, carbonic anhydrase, or NOS did not show any effects (96).

Nitrite-derived NO production participates in heterocellular communication in blood. Thus, studies have shown that nitrite bioactivation by RBCs inhibits platelet activation/ aggregation, while nitrite alone has no effects $(96,108)$. These data show that nitrite-derived NO production may participate in heterocellular signaling in the blood stream. How mechanical forces influence scavenging or production of NO under hypoxic conditions by RBCs and the heterocellular signaling needs to be further elucidated.

Red cell eNOS-dependent NO production: normoxic conditions. Data from our and other laboratories have demonstrated eNOS-dependent NO production from RBCs in normoxia, suggesting that RBCs may contribute to inhibition of platelet aggregation (88), the circulating pool of NO metabolites (88), and thus to overall tissue protection (155). Treating RBCs with eNOS inhibitors decreased accumulation of NO metabolites $(75,88)$ and L-citrulline in the supernatant $(88,155)$. By applying a multilevel analytical approach comprising HPLC, LC-MS/MS, flow cytometry, laser scanning microscopy, and enzymatic assays together with functional studies, we have recently demonstrated that human RBCs contain an active eNOS building NO formation under normoxic conditions $(29,30)$. To biochemically characterize the eNOS expressed in RBCs, we established an immunoprecipitation protocol by using magnetic beads and a purified mouse anti-human eNOS antibody, which was chemically cross-linked to the beads. By applying this protocol, we were able to isolate eNOS from human (30) and mouse RBCs (153). The identity of human red cell eNOS was confirmed by ESI-MS/MS (30). The activity of the protein was assessed by measuring the conversion of ${ }^{3} \mathrm{H}-$ or ${ }^{14} \mathrm{C}$ arginine to ${ }^{3} \mathrm{H}$ - or ${ }^{14} \mathrm{C}$-citrulline catalyzed by the immunoprecipitated eNOS (30) and membrane preparations of RBCs (153). We found that the isolated eNOS protein was $\mathrm{Ca}^{2+} /$ $\mathrm{CaM}$ dependent (30), could be inhibited in the presence of NOS inhibitors (L-NAME, L-NIO) (30), and its activity was absent in RBC membrane preparations from eNOS knockout (KO) mice (153).

NO was proposed to regulate RBC deformability (15). NOS inhibitors were shown to decrease RBC deformability in ektacytometry (15), while low concentrations of NO donors increase RBC deformability (15), membrane fluidity (138), and RBC filterability (88). However, the role of NO in human RBC deformability is controversial (12). In the microcirculation of the chorioallantoic membrane of the chicken egg, eNOS inhibition and NO donors were shown to affect RBC deformation and velocity independently of changes of the vascular diameter (75). The role of red cell eNOS in RBC signaling is still unknown.

RBCs as NO producers: how does NO survive the reaction with hemoglobin in RBCs?. According to the findings reviewed in the previous paragraphs, there is compelling evidence that RBCs produce NO under both hypoxic and normoxic conditions. However, taking into account the chemical biology of the reactions between $\mathrm{NO}$ and hemoglobin, one may conclude that any NO produced within an RBC will react with hemoglobin under any physiological condition under consideration, that is, with oxyhemoglobin to form nitrate and methemoglobin (Eq. 1), as well as with deoxyhemoglobin to form nitrosylhemoglobin (Eq. 2) (73):

$$
\mathrm{Fe}^{\mathrm{II}} \mathrm{Hb}+\mathrm{NO} \rightarrow \mathrm{Fe}^{\mathrm{II}} \mathrm{NOHb}
$$

Thus, the main open question still to be answered is how NO produced within the RBC may survive the reaction with hemoglobin. It was proposed that compartmentalization of NO production in RBCs by formation of protein complexes on the RBC membrane (e.g., deoxyHb, AE1/band 3, and $\mathrm{Rh}$-protein channels) facilitates NO production under hypoxic conditions and its export (60). Recently, it was shown that deoxyhemoglobin forms a complex with band 3 on the membrane of RBCs and that the stability of the complex depends on the oxygenation state of hemoglobin (124). Another possibility proposed by us is the presence of specific protein targets within the RBCs, leading to activation of downstream signaling and or protection of $\mathrm{NO}$ by local conversion of hemoglobin into methemoglobin (28). More research is needed to understand how NO may survive scavenging by hemoglobin as well as to understand the role of NO production in RBC signaling and heterocellular communication.

\section{Mechanosensing and mechanotransduction in RBCs}

RBCs are mechanosensing cells that respond to mechanical forces by changing their shape. RBC deformation is a complex dynamic process mediated by aggregation and disaggregation of interactions among cytoskeletal and membrane proteins $(52,143,144)$. $R B C$ deformability ${ }^{c}$ is required for an efficient delivery of oxygen and nutrients to the tissues (19) and contributes to define the rheological properties of blood (143). RBC deformability may modulate the viscosity

\footnotetext{
'According to literature describing the rheological and mechanical properties of $\mathrm{RBCs}$, the term deformability indicates the capacity or potential of RBCs to change their shape (which is studied in rheological devices such as ektacytometers), while the term deformation describes the dynamical process of shape change.
} 
of blood and importantly allows the cells to dynamically participate in the flow by adapting their shape to the different flow conditions found in conductance and resistance vessels and in the microcirculation (143). Moreover, RBCs need to deform to be able to enter and transit the narrowest capillaries of the microcirculation, which may be even narrower than their own diameter (143). Capillary blood flow and RBC velocity in the microcirculation strongly depend on vascular tone and RBC deformability (143).

It was shown that in response to shear stress, $\mathrm{RBCs}$ release ATP, which may act as a mechanotransducer and bind to the purinergic receptors on the endothelium, activating eNOSderived NO formation and heterocellular signaling leading to vasorelaxation and increased blood flow $(43,99,143)$. Recently, Stone and coworkers applied a microfluidic approach to study the time-dependent dynamics of deformationinduced ATP release from RBCs (144) and demonstrated a link between shear stress-mediated mechanical deformation of RBCs and release of ATP $(52,144)$. Several key elements in the mechanotransduction pathways of ATP release from RBCs, including GPCR and hemichannels, such as the ubiquitous ATP-releasing channel pannexin-1, have been proposed (144), but not investigated in detail. Recently, it was found that shear stress activates PIEZO-1 cation channel inducing $\mathrm{Ca}^{2+}$ influx and ATP release from RBCs (26). Noteworthy, the absence of $\mathrm{Ca}^{2+}$ in the incubation medium did not fully block ATP release from RBCs, indicating that $\mathrm{Ca}^{2+}$ independent mechanotransduction pathways are present in RBCs (26). A methodological article by Sikora et al. proposed that the experimental conditions described in the literature to induce ATP release caused hemolysis, and therefore hemolysis and not the activation of signaling pathways in RBCs (including mechanosensing and mechanotransduction) was causing the increase in ATP in the supernant of RBC suspensions (131). This article started a lively discussion (87). In our opinion, the conclusions of this article are not fully justified by the results provided because of some methodological issues, including the use of a vortex for inducing shear stress on RBCs. As pointed out by many authors in the field (26, 143), controlling for hemolysis and effects of vehicle in drug application is fundamental before driving conclusions about signaling in RBCs. Indeed, research with RBCs is not without its pitfalls as we already discussed in a recent review (28).

Considering the central role of eNOS activation in mechanotransduction within the endothelium, it is tempting to speculate that red cell eNOS may participate in mechanotransduction in RBCs, inducing intracellular signaling and NO-mediated regulation.

\section{Summary and outlook: mechanical forces and luminal heterocellular communication}

The role of mechanical forces in NO scavenging, transport, and synthesis in RBCs and their interaction with platelets and endothelium is not understood yet. The rheological behavior of RBCs in the flow of conduit vessels (where RBCs accumulate in the center of the vessel leaving a cell-free zone near the endothelium) was proposed as one of the mechanisms for limiting endothelial NO scavenging by RBCs allowing NO to control vascular tone and blood pressure. Mechanical forces and flow conditions are known to regulate aggregability and activation of platelets. Similarly, the action of mechanical forces on the cytoskeleton of RBCs may regulate their deformation, e.g. via modulation of aggregation/disaggregation of protein complexes regulating deformability, as well as erythrocrine function, including synthesis, signaling, or export of NO from RBCs or ATP release. Therefore, investigations on the role of mechanical forces on RBC-mediated NO production may be of fundamental importance to fully understand the role of RBCs in NO metabolism and transport under flow conditions.

\section{Systemic Heterocellular Communication Induced by Physical Forces}

In this paragraph, we will describe how increase of vascular shear may modulate systemic heterocellular signaling, leading to improvement of cardiovascular function, and will highlight the role of endothelial NO in initiation and induction of these favorable systemic changes. The effects of exercise training and remote ischemic preconditioning are described as examples of complex systemic physiological responses to changes in shear (Figs. 4 and 5).

\section{Role of eNOS in vascular adaptation to exercise}

Moderate exercise training has proven to be efficient to prevent cardiovascular disease conditions in a multitude of observations and studies (126). Regular physical activity promotes a variety of favorable changes and adaptations of cardiovascular function, including reduction of blood pressure (16) and inhibition of atherogenesis (111). Exercise training acutely increases heart rate and blood flow, thus changing frequency and magnitude of hemodynamic forces (Fig. 4). During exercise, vascular cells are simultaneously exposed to very heterogeneous spatial and temporal stresses, such as shear stress, cyclic strain, and transmural pressure. In the long-term view, regular exercise training results in alterations of endothelial gene expression pattern, that is, upregulation of atheroprotective and downregulation of potentially atherogenic genes (147), which likely lead to protection of vascular cells against apoptosis, inflammation, and oxidative stress.

Exercise-induced eNOS upregulation and increased endothelial-dependent vasodilation were first observed in dog coronary arteries (54) and then confirmed in many other studies $(59,66,135)$. Likewise, experiments conducted in different animal models and humans revealed that exercise activates a complex pattern of intracellular eNOS regulatory systems, including changes in phosphorylation state, and intracellular localization (59). Furthermore, beneficial effects of training on vascular endothelial function attributed to the increased vascular NO bioavailability and upregulation of eNOS were reported in patients with coronary artery disease (66) and chronic heart failure (151). Recent studies demonstrated that high-density lipoprotein (HDL) can modulate the phosphorylation of eNOS and thereby its activity; interestingly, HDL-mediated eNOS activation was significantly impaired in cardiovascular disease patients, but can be restored by regular exercise (2). Therefore, mild to moderate exercise training may be beneficial even in conditions previously considered as contraindications (e.g., heart failure after coronary bypass grafting).

The effects of exercise training on eNOS expression and phosphorylation profile are influenced by a number of factors 


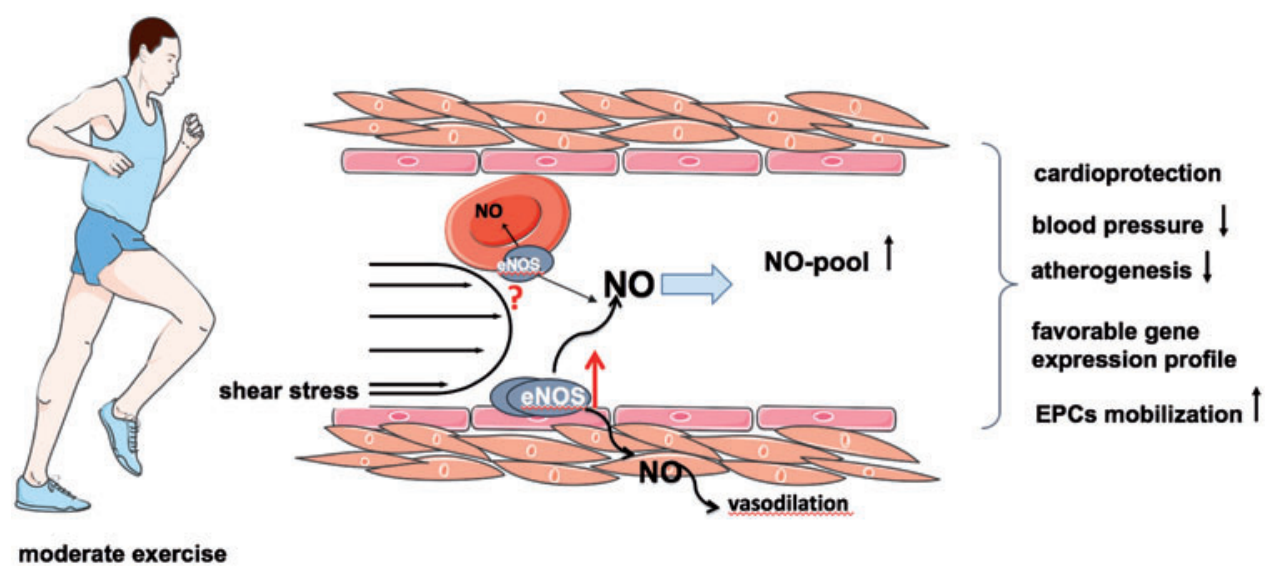

FIG. 4. Vascular adaptation to exercise. Some of the beneficial cardiovascular adaptations to exercise are attributed to upregulation of eNOS and systemic increase of NO bioavailability, which may result in a reduction of blood pressure, decreased atherogenesis, and increase in mobilization of EPCs, as well as in induction of protective genes in the vasculature and cardioprotection. Whether shear stress also activates red cell eNOS is still under investigation. EPC, endothelial progenitor cell. To see this illustration in color, the reader is referred to the web version of this article at www.liebertpub.com/ars

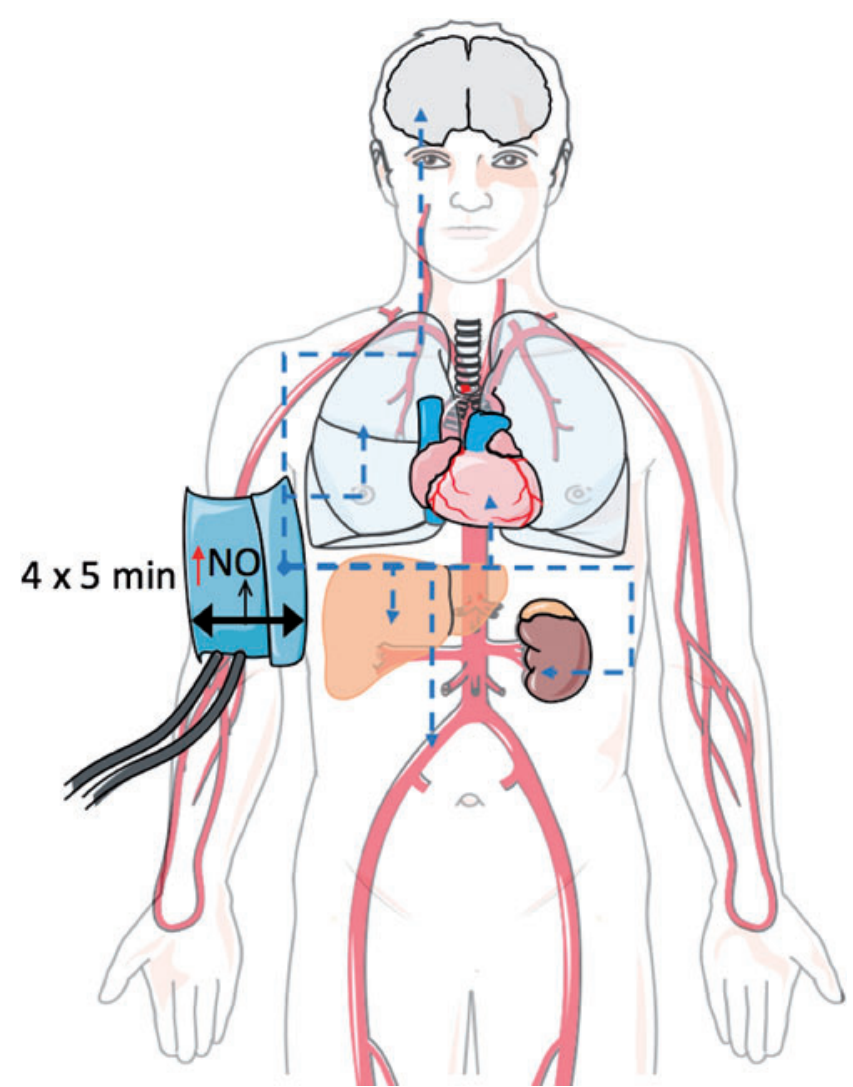

FIG. 5. Remote ischemic preconditioning (rIPC). The picture illustrates the protective effects of rIPC maneuver, induced by four cycles of $5 \mathrm{~min}$ of occlusion, followed by 5 min of reperfusion, inducing a repetitive increase in shear stress accompanied by mechanotransduction, including eNOS activation and NO release. The blue arrows indicate transduction of protective signals from the vessel endothelium of the brachial arteries to the brain, lung, heart, liver, kidney, and other vessels. To see this illustration in color, the reader is referred to the web version of this article at www.liebertpub.com/ars such as training time, exercise intensity, basal level of physical activity, and eNOS gene polymorphisms (89). Furthermore, since blood flow and hemodynamic shear forces strongly depend on the localization and morphology of the vessels along the vascular tree (22), the effect of exercise on vascular eNOS may differ in various regions (35). These effects are particularly evident for regions near arterial branches and curves, which are characterized by disturbed flow conditions (22). In contrast to the laminar flow in large conductance arteries, oscillatory shear can reduce eNOS expression and thus elicit a proinflammatory endothelial phenotype $(35,89)$. In fact, these regions are known to be more prone to development of atherosclerosis $(22,25)$. The impact of exercise training on vascular responsiveness and endothelial function in different regions of the circulation needs to be investigated in more detail.

Numerous studies provided evidence for exercise-induced mobilization of endothelial progenitor cells (EPCs) from the bone marrow to the circulation (93) and thus its contribution to the vascular regeneration and angiogenesis (9). The mechanisms of EPC mobilization from the bone marrow are highly complex (4) and depend on the activation of eNOS in the presence of numerous mobilizing factors (e.g., VEGF, placental growth factor). Experimental studies have shown that mobilization of stem and progenitor cells in vivo from the bone marrow stromal cells is substantially eNOS dependent (3) and due to activation of matrix metalloproteinases 2 and 9 (79). Interestingly, exercise-induced EPC mobilization is abolished in the eNOS-deficient mouse strain (91).

\section{Remote ischemic preconditioning}

Already in 1986, Murry at al. observed that repetitive brief periods of occlusion of a coronary artery before cardiac ischemia can reduce the infarct sizes in a canine model, a phenomenon defined as ischemic preconditioning (105). Przyklenk et al. found that the effects of ischemia were cardioprotective, even if carried out in another area of the heart (112). Further studies demonstrated that a preconditioning maneuver is cardioprotective even if performed in noncardiac tissues (57). It was proposed that brief 
reversible episodes of ischemia and reperfusion may result in release of a protective signal from the site of ischemia and result in cardioprotection (67). Proposed mechanisms include neuronal transmission (152) [although criticized by others (90)] as well as may involve humoral mediators such as adenosine, BK, opioids, angiotensin I, and endocannabinoids (68). Rassaf et al. observed that nitrite levels in plasma are increased as a result of the preconditioning maneuver and that preconditioning is ineffective in eNOS KO mice (117). They have suggested that preconditioning-activated eNOS-derived formation of NO in the endothelium (probably via changes in shear stress) leads to increase of circulating nitrite levels and cardioprotection via myoglobin-dependent conversion of nitrite into NO and nitrosation of complex 1 (117). These studies demonstrate that shear stress-induced NO production within the endothelium may result in local heterocellular communication within the vasculature or to the blood cells upon biotransformation of NO into stable bioactive metabolites transported within the plasma or RBCs.

\section{Summary and outlook: systemic signaling induced local and hemodynamic forces}

Taken together, there is evidence that changing frequency or magnitude of hemodynamic forces by systemic changes (such as in exercise training) or locally (such as by temporary arterial occlusion in remote ischemic preconditioning) may induce short-term and long-term changes in vascular NO production and lead to protection of heart and vessels, as well as other tissues (Figs. 1, 4, and 5).

\section{Critical Issues for Experimental Studies}

Mechanical forces affect a number of different cell types in the human body. Our understanding of the complex heterocellular communication induced by mechanical forces in the organism has evolved from investigations using in vitro, ex vivo, and in vivo methods. Each of these approaches can provide only partial information about the complex and intertwined effects of mechanical forces and the induced local and systemic heterocellular signaling in the organism.

The cellular effects of physical forces were mainly studied usually by applying nonpulsatile shear stress and by analyzing the behavior of endothelial cell monolayers in culture in the absence or in the presence of blood cells in microfluidic devices (140). These in vitro experiments revealed, for example, that the laminar flow modulates endothelial cell morphology, adhesion molecules, and gene expression patterns, secretion of extracellular matrix proteins, and cell-cell and cell-matrix adhesions and orchestrates collective behaviors of adherent cells (10). Similar devices were also applied for studying platelet aggregation in response to vascular injury involving exposure of the extracellular matrix found below the endothelium $(113,130)$.

Microfluidic technology enables studies of cell behavior from single- to multicellular organism levels. The true potential of the use of microfluidics has emerged recently with the advent of hydrogel systems, offering increased throughput, multicellular interactions, substrate functionalization on three-dimensional (3D) geometries, and simultaneous control of chemical and mechanical stimulation (140). Applications of 3D cell culture systems for analysis of cell-cell interactions under flow conditions may provide a proper environ- ment to study 3D cell-cell interactions and heterocellular communication in response to mechanical forces.

The isolated/perfused Langendorff heart is traditionally applied to analyze coronary function and changes in coronary flow in response to brief ischemia/reperfusion periods or to pharmacological stimuli. This technique was also applied to analyze the effects of RBCs on tissue oxygenation conditions, coronary vascular response, and myocardial performance and oxygen consumption (24). Likewise, endothelium-dependent and -independent coronary flow responses were increased in RBC-perfused hearts (24). Recently, the cardioprotective effects of red cell eNOS (via activation of arginase-1) toward ischemia were demonstrated by application of this method (156). Foaming, hemolysis, and isolation of the heart, as well as stability of the preparation, make this technique technically demanding. Therefore, it is necessary to integrate this set of heterogeneous information to improve our understanding of these mechanisms.

In vivo investigations in animal models are the best available tools for evaluation of systemic hemodynamics and blood cells/luminal components in shear stress-induced heterocellular communication. Modulation of systemic heterocellular communication can be studied by combining genetic approaches (e.g., eNOS KO mice) with physiological stimuli, which are known to increase shear/hemodynamic forces, for example, forced and voluntary exercise (134) and remote ischemic preconditioning (117). To untangle the role of vascular and blood components responsible for eNOSmediated heterocellular signaling, we created chimera mice by bone marrow transplantation $(103,153)$. Applying this approach, we found that blood cell eNOS participates in regulation of blood pressure and cardioprotection. Although useful, this approach presents some methodological limitations, including irradiation-dependent activation of inflammatory pathways (which may increase the expression of an inducible NOS), the possibility of protein transfer from the blood to the endothelium (due to housing of circulating EPCs), the presence of low levels of circulating blood cells from the recipient, and-most importantly-the lack of blood cell lineage targeting specificity.

Development of inducible and conditional transgenic mice with tissue-specific target expression or ablation of genes important for regulation of NO bioavailability and mechanotransduction may overcome these limitations.

Taking together, investigations in tissue-specific transgenic mice applying a wide range of in vitro, ex vivo, and in vivo approaches represent a future strategy to unravel the complexity of NO-mediated, shear-induced heterocellular signaling and will help to identify new potential molecular targets and strategies for therapeutical, pharmacological, and nonpharmacological interventions aiming to reduce cardiovascular disease.

\section{Clinical Aspects: Mechanotransduction in Endothelial Dysfunction}

Alterations in endothelial function and the functional integrity of the endothelium are associated with a variety of pathological conditions, including hypertension, diabetes mellitus, hypercholesterolemia, and heart failure (49). Likewise, primary and secondary risk factors such as age, smoking, or hypercholesterolemia have been correlated with a decrease in endothelial function (Fig. 6 and Supplementary Table S1). 


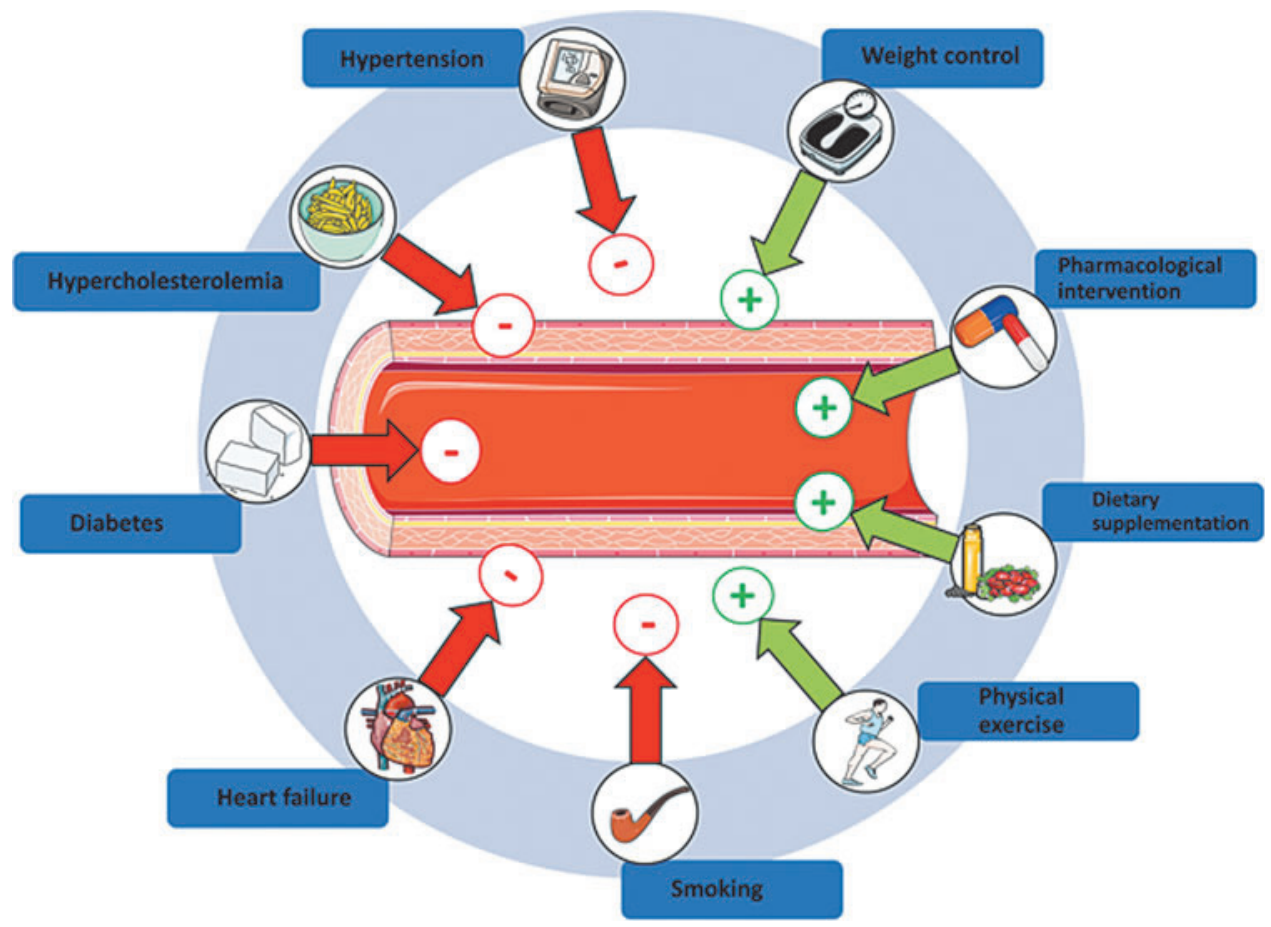

FIG. 6. Conditions influencing endothelial function. Red arrows highlight conditions inducing adverse effects on endothelial function, whereas green arrows represent treatments/conditions exerting beneficial effects on endothelial function. Please refer to Supplementary Table S1 (Supplementary Data are available online at www .liebertpub.com/ars) for literature references. To see this illustration in color, the reader is referred to the web version of this article at www.liebertpub .com/ars

Measurement of endothelial function allows assessment of the patients' risk of cardiovascular events, progression of atherosclerosis-related conditions, efficacy of lifestyle changes/ pharmacological intervention, and patient stratification (Fig. 6 and Supplementary Table S1). Interestingly, shear-induced eNOS-dependent activation of vascular heterocellular communication constitutes the molecular basis of all methods applied in the clinical routine for evaluation of endothelial function. Assessment of FMD of the brachial artery by highresolution ultrasound is one of the most widely applied methods for noninvasive evaluation of endothelial function in clinical setting (72). Analysis of changes in reactive hypermemic response by laser Doppler perfusion imaging was proposed for evaluation of microcirculatory function (86). Clinical studies based on administration of specific NOS inhibitors have shown that the FMD response is strongly dependent on eNOS activity (72). Indeed, FMD correlates with levels of circulating nitrosospecies in plasma (70), and mice lacking eNOS show no FMD response $(44,125)$. Interestingly, the same experimental setting allowed showing that low flow conditions (achieved during occlusion) induce eNOS-independent vasoconstriction, as demonstrated in man (62) and in mice (44). These data provide a further experimental proof of responsiveness and sensitivity of the endothelium to different acute changes of flow conditions and highlight the fundamental role played by eNOS in physiological and pathophysiological shear-induced heterocellular signaling in the human vasculature.

According to the guidelines of the American Heart Association (42) and the European Society of Cardiology (110), the most effective treatments preventing the development or progression of endothelial dysfunction are lifestyle changes, including a low-calorie and low-fat diet, as well as regular exercise, reduction of alcohol consumption, and smoking cessation. These strategies, together with pharmacological interventions aiming to reduce blood pressure or/and hypercholesterolemia, have been shown to decrease morbidity and mortality of cardiovascular disease (121). Understanding how mechanotransduction and changes in NO bioavailability contribute to local and systemic heterocellular communication will help in identifying novel diagnostic and therapeutic targets for prevention of cardiovascular disease.

\section{Summary and Future Directions}

NO produced by the vascular endothelium is a key mechanotransducer for local and systemic heterocellular communication. The endothelium is well equipped with different mechanosensors found on the luminal side of the membrane (such as glycocalyx, ion channels, and GPCRs), in the junctional structures responsible for cell-cell interactions (such as the VEGFR2/PECAM-1/VE-cadherin complex), in focal adhesion points (such as integrins), or inside cells (such as the cytoskeleton or tyrosine kinases such as Pyk2). Mechanosensors are activated by local changes in blood flow and elicit transformation of flow-induced mechanical stimulation into biochemical signals, which are then transduced within the cells and across cells, finally leading to activation of local and systemic responses.

Laminar shear stress is now considered as one of the most important physiological stimuli for activation of eNOS within the endothelium and it is responsible for NO-mediated local and systemic heterocellular communication leading to regulation of vascular tone, blood pressure, and blood hemostasis. Interestingly, not only vascular cells but also RBCs and platelets are capable of sensing mechanical forces and inducing specific signaling mechanisms to modulate heterocellular communication in the blood stream and in the vasculature. NO produced by the endothelium in response to mechanical forces can be metabolized in RBCs, plasma, and other tissues and can be transported in the form of different metabolites in the blood stream; in turn, bioactive NO metabolites allow sheardependent systemic heterocellular signaling (Fig. 1).

Exercise training and remote ischemic preconditioning represent two beneficial examples of effective systemic 
NO-mediated heterocellular communication in response to physiological shear. Systemic shear-induced NO-mediated communication between the endothelium and other cells is highly complex and new experimental approaches are needed to differentiate the specific role of each cell population in modulation of systemic cell-cell communication and signaling. Under pathological conditions, changes in mechanical properties of the vessel endothelium may limit NO production/bioavailability affecting systemic hemodynamics, vascular tone, and overall cardiovascular homeostasis.

Future studies are needed to unravel mechanisms underpinning changes in heterocellular communications among endothelium and other cell types in response to mechanical forces. These studies will help to identify novel therapeutic strategies, including pharmacological and nonpharmacological interventions, to modify mechanosensing and mechanotransductiondependent heterocellular signaling in health and disease.

\section{Acknowledgments}

The authors are grateful to the German Research Council (DFG CO 1305/2-1 to M.M.C.-K., SFB1116 TP B06 to M.M.C.-K. and M.K., and IRTG1902 to M.K. and M.M.C.K.), to the Forschungskommission of the Universitätsklinikum Düsseldorf (to M.M.C.-K. and to T.S.), and the SusanneBunnenberg-Stiftung of the Düsseldorf Heart Center (to M.K.) for financial support.

\section{References}

1. Aamand R, Dalsgaard T, Jensen FB, Simonsen U, Roepstorff A, and Fago A. Generation of nitric oxide from nitrite by carbonic anhydrase: a possible link between metabolic activity and vasodilation. Am J Physiol Heart Circ Physiol 297: H2068-H2074, 2009.

2. Adams V, Besler C, Fischer T, Riwanto M, Noack F, Höllriegel R, Oberbach A, Jehmlich N, Völker U, Winzer EB, Lenk K, Hambrecht R, Schuler G, Linke A, Landmesser U, and Erbs S. Exercise training in patients with chronic heart failure promotes restoration of high-density lipoprotein functional properties. Circ Res 113: 1345-1355, 2013.

3. Aicher A, Heeschen C, Mildner-Rihm C, Urbich C, Ihling C, Technau-Ihling K, Zeiher AM, Dimmeler S. Essential role of endothelial nitric oxide synthase for mobilization of stem and progenitor cells. Nat Med 9: 1370-1376, 2003.

4. Aicher A, Zeiher AM, and Dimmeler S. Mobilizing endothelial progenitor cells. Hypertension 45: 321-325, 2005.

5. Altaany Z, Ju Y, Yang G, and Wang R. The coordination of S-sulfhydration, S-nitrosylation, and phosphorylation of endothelial nitric oxide synthase by hydrogen sulfide. Sci Signal 7: ra87, 2014.

6. Anand P and Stamler JS. Enzymatic mechanisms regulating protein S-nitrosylation: implications in health and disease. J Mol Med (Berl) 90: 233-244, 2012.

7. Ando $\mathrm{J}$ and Yamamoto K. Vascular mechanobiology: endothelial cell responses to fluid shear stress. Circ J 73: 1983-1992, 2009.

8. Arnold WP, Mittal CK, Katsuki S, and Murad F. Nitric oxide activates guanylate cyclase and increases guanosine $3^{\prime}: 5^{\prime}$-cyclic monophosphate levels in various tissue preparations. Proc Natl Acad Sci U S A 74: 3203-3207, 1977.
9. Asahara T, Murohara T, Sullivan A, Silver M, van der ZR, Li T, Witzenbichler B, Schatteman G, and Isner JM. Isolation of putative progenitor endothelial cells for angiogenesis. Science 275: 964-967, 1997.

10. Balligand J-L, Feron O, and Dessy C. eNOS activation by physical forces: from short-term regulation of contraction to chronic remodeling of cardiovascular tissues. Physiol Rev 89: 481-534, 2009.

11. Bassand JP, Afzal R, Eikelboom J, Wallentin L, Peters R, Budaj A, Fox KA, Joyner CD, Chrolavicius S, Granger $\mathrm{CB}$, Mehta S, and Yusuf S. Relationship between baseline haemoglobin and major bleeding complications in acute coronary syndromes. Eur Heart J 31: 50-58, 2010.

12. Belanger AM, Keggi C, Kanias T, Gladwin MT, and KimShapiro DB. Effects of nitric oxide and its congeners on sickle red blood cell deformability. Transfusion 55: 2464 2472, 2015.

13. Blackmore PF. Biphasic effects of nitric oxide on calcium influx in human platelets. Thromb Res 127: e8-e14, 2011.

14. Bohme E, Jung R, and Mechler I. Guanylate cyclase in human platelets. Methods Enzymol 38: 199-202, 1974.

15. Bor-Kucukatay M, Wenby RB, Meiselman HJ, and Baskurt OK. Effects of nitric oxide on red blood cell deformability. Am J Physiol Heart Circ Physiol 284: H1577-H1584, 2003.

16. Bowles DK and Wamhoff BR. Coronary smooth muscle adaptation to exercise: does it play a role in cardioprotection? Acta Physiol Scand 178: 117-121, 2003.

17. Bryan NS, Rassaf T, Maloney RE, Rodriguez CM, Saijo F, Rodriguez JR, and Feelisch M. Cellular targets and mechanisms of nitros(yl)ation: an insight into their nature and kinetics in vivo. Proc Natl Acad Sci U S A 101: 43084313, 2004.

18. Busse $\mathrm{R}$ and Mülsch A. Calcium-dependent nitric oxide synthesis in endothelial cytosol is mediated by calmodulin. FEBS Lett 265: 133-136, 1990.

19. Cabrales P. Effects of erythrocyte flexibility on microvascular perfusion and oxygenation during acute anemia. Am J Physiol Heart Circ Physiol 293: 1206-1215, 2007.

20. Chachisvilis M, Zhang Y-L, and Frangos JA. G proteincoupled receptors sense fluid shear stress in endothelial cells. Proc Natl Acad Sci U S A 103: 15463-15468, 2006.

21. Chatterjee $S$ and Fisher AB. Mechanotransduction in the endothelium: role of membrane proteins and reactive oxygen species in sensing, transduction, and transmission of the signal with altered blood flow. Antioxid Redox Signal 20: 899-913, 2014.

22. Chatzizisis YS, Coskun AU, Jonas M, Edelman ER, Feldman CL, and Stone PH. Role of endothelial shear stress in the natural history of coronary atherosclerosis and vascular remodeling: molecular, cellular, and vascular behavior. J Am Coll Cardiol 49: 2379-2393, 2007.

23. Chen C-A, Wang T-Y, Varadharaj S, Reyes LA, Hemann C, Talukder MAH, Chen Y-R, Druhan LJ, and Zweier JL. S-glutathionylation uncouples eNOS and regulates its cellular and vascular function. Nature 468: 1115-1118, 2010.

24. Chen V, Chen YH, and Downing SE. An improved isolated working rabbit heart preparation using red cell enhanced perfusate. Yale J Biol Med 60: 209-219, 1987.

25. Chiu JJ and Chien S. Effects of disturbed flow on vascular endothelium: pathophysiological basis and clinical perspectives. Physiol Rev 91: 327-387, 2011.

26. Cinar E, Zhou S, DeCourcey J, Wang Y, Waugh RE, and Wan J. Piezo1 regulates mechanotransductive release of 
ATP from human RBCs. Proc Natl Acad Sci U S A 112: 11783-11788, 2015.

27. Cortese-Krott MM, Butler AR, Woollins JD, and Feelisch M. Inorganic sulfur-nitrogen compounds: from gunpowder chemistry to the forefront of biological signaling. Dalton Transact 45: 5908-5919, 2016.

28. Cortese-Krott MM and Kelm M. Endothelial nitric oxide synthase in red blood cells: key to a new erythrocrine function? Redox Biol 2: 251-258, 2014.

29. Cortese-Krott MM, Rodriguez-Mateos A, Kuhnle GG, Brown G, Feelisch M, and Kelm M. A multilevel analytical approach for detection and visualization of intracellular NO production and nitrosation events using diaminofluoresceins. Free Radic Biol Med 53: 2146-2158, 2012.

30. Cortese-Krott MM, Rodriguez-Mateos A, Sansone R, Kuhnle GG, Thasian-Sivarajah S, Krenz T, Horn P, Krisp C, Wolters D, Heiss C, Kroncke KD, Hogg N, Feelisch M, and Kelm M. Human red blood cells at work: identification and visualization of erythrocytic eNOS activity in health and disease. Blood 120: 4229-4237, 2012.

31. Cosby K, Partovi KS, Crawford JH, Patel RP, Reiter CD, Martyr S, Yang BK, Waclawiw MA, Zalos G, Xu X, Huang KT, Shields H, Kim-Shapiro DB, Schechter AN, Cannon Iii RO, and Gladwin MT. Nitrite reduction to nitric oxide by deoxyhemoglobin vasodilates the human circulation. Nat Med 9: 1498-1505, 2003.

32. Craven PA and DeRubertis FR. Restoration of the responsiveness of purified guanylate cyclase to nitrosoguanidine, nitric oxide, and related activators by heme and hemeproteins. Evidence for involvement of the paramagnetic nitrosyl-heme complex in enzyme activation. $J$ Biol Chem 253: 8433-8443, 1978.

33. Dangel O, Mergia E, Karlisch K, Groneberg D, Koesling $\mathrm{D}$, and Friebe A. Nitric oxide-sensitive guanylyl cyclase is the only nitric oxide receptor mediating platelet inhibition. J Thromb Haemostasis 8: 1343-1352, 2010.

34. Davies PF. Flow-mediated endothelial mechanotransduction. Physiol Rev 75: 519-560, 1995.

35. Davies PF, Civelek M, Fang Y, and Fleming I. The atherosusceptible endothelium: endothelial phenotypes in complex haemodynamic shear stress regions in vivo. Cardiovasc Res 99: 315-327, 2013.

36. Davis ME, Cai H, Drummond GR, and Harrison DG. Shear stress regulates endothelial nitric oxide synthase expression through c-Src by divergent signaling pathways. Circ Res 89: 1073-1080, 2001.

37. Defilippi P, van Hinsbergh V, Bertolotto A, Rossino P, Silengo L, and Tarone G. Differential distribution and modulation of expression of alpha 1 /beta 1 integrin on human endothelial cells. J Cell Biol 114: 855-863, 1991.

38. Dejam A, Hunter CJ, Pelletier MM, Hsu LL, Machado RF, Shiva S, Power GG, Kelm M, Gladwin MT, and Schechter AN. Erythrocytes are the major intravascular storage sites of nitrite in human blood. Blood 106: 734739, 2005.

39. Deonikar P and Kavdia M. Contribution of membrane permeability and unstirred layer diffusion to nitric oxidered blood cell interaction. J Theor Biol 317: 321-330, 2013.

40. Dimmeler S, Fleming I, Fisslthaler B, Hermann C, Busse $\mathrm{R}$, and Zeiher AM. Activation of nitric oxide synthase in endothelial cells by Akt-dependent phosphorylation. Nature 399: 601-605, 1999.
41. Doyle MP and Hoekstra JW. Oxidation of nitrogen oxides by bound dioxygen in hemoproteins. J Inorg Biochem 14: 351-358, 1981.

42. Eckel RH, Jakicic JM, Ard JD, de Jesus JM, Houston Miller N, Hubbard VS, Lee I-M, Lichtenstein AH, Loria CM, Millen BE, Nonas CA, Sacks FM, Smith SC, Svetkey LP, Wadden TA, Yanovski SZ; and American College of Cardiology/American Heart Association Task Force on Practice Guidelines. 2013 AHA/ACC guideline on lifestyle management to reduce cardiovascular risk: a report of the American College of Cardiology/American Heart Association Task Force on Practice Guidelines. J Am Coll Cardiol 63: 2960-2984, 2014.

43. Ellsworth ML and Sprague RS. Regulation of blood flow distribution in skeletal muscle: role of erythrocytereleased ATP. J Physiol 590: 4985-4991, 2012.

44. Erkens R, Kramer CM, Luckstadt W, Panknin C, Krause L, Weidenbach M, Dirzka J, Krenz T, Mergia E, Suvorava T, Kelm M, and Cortese-Krott MM. Left ventricular diastolic dysfunction in Nrf2 knock out mice is associated with cardiac hypertrophy, decreased expression of SERCA2a, and preserved endothelial function. Free Radic Biol Med 89: 906-917, 2015.

45. Erwin PA, Lin AJ, Golan DE, and Michel T. Receptorregulated dynamic S-nitrosylation of endothelial nitricoxide synthase in vascular endothelial cells. $J$ Biol Chem 280: 19888-19894, 2005.

46. Feelisch M and Martin JF. The early role of nitric oxide in evolution. Trends Ecol Evol 10: 496-499, 1995.

47. Feelisch M, Rassaf T, Mnaimneh S, Singh N, Bryan NS, Jourd'Heuil D, and Kelm M. Concomitant S-, N-, and heme-nitros(yl)ation in biological tissues and fluids: implications for the fate of NO in vivo. FASEB J 16: 17751785, 2002.

48. Fisslthaler B, Loot AE, Mohamed A, Busse R, and Fleming I. Inhibition of endothelial nitric oxide synthase activity by proline-rich tyrosine kinase 2 in response to fluid shear stress and insulin. Circ Res 102: 1520-1528, 2008.

49. Flammer AJ, Anderson T, Celermajer DS, Creager MA, Deanfield J, Ganz P, Hamburg NM, Lüscher TF, Shechter M, Taddei S, Vita JA, and Lerman A. The assessment of endothelial function: from research into clinical practice. Circulation 126: 753-767, 2012.

50. Fleming I. Molecular mechanisms underlying the activation of eNOS. Pflugers Arch 459: 793-806, 2010.

51. Fleming I, Fisslthaler B, Dixit M, and Busse R. Role of PECAM-1 in the shear-stress-induced activation of Akt and the endothelial nitric oxide synthase (eNOS) in endothelial cells. J Cell Sci 118: 4103-4111, 2005.

52. Forsyth AM, Wan J, Owrutsky PD, Abkarian M, and Stone HA. Multiscale approach to link red blood cell dynamics, shear viscosity, and ATP release. Proc Natl Acad Sci U S A 108: 10986-10991, 2011.

53. Fukuto JM, Carrington SJ, Tantillo DJ, Harrison JG, Ignarro LJ, Freeman BA, Chen A, and Wink DA. Small molecule signaling agents: the integrated chemistry and biochemistry of nitrogen oxides, oxides of carbon, dioxygen, hydrogen sulfide, and their derived species. Chem Res Toxicol 25: 769-793, 2012.

54. Fulton D, Papapetropoulos A, Zhang XP, Catravas JD, Hintze TH, and Sessa WC. Quantification of eNOS mRNA in the canine cardiac vasculature by competitive PCR. Am J Physiol Heart Circ Physiol 278: H658-H665, 2000. 
55. Gambaryan S, Friebe A, and Walter U. Does the NO/sGC/ cGMP/PKG pathway play a stimulatory role in platelets? Blood 119: 5335-5336; author reply 5336-5337, 2012.

56. Gambaryan S, Subramanian H, Rukoyatkina N, Herterich $\mathrm{S}$, and Walter U. Soluble guanylyl cyclase is the only enzyme responsible for cyclic guanosine monophosphate synthesis in human platelets. Thromb Haemost 109: 973975, 2013.

57. Gho BC, Schoemaker RG, van den Doel MA, Duncker DJ, and Verdouw PD. Myocardial protection by brief ischemia in noncardiac tissue. Circulation 94: 2193-2200, 1996.

58. Ghosh SM, Kapil V, Fuentes-Calvo I, Bubb KJ, Pearl V, Milsom AB, Khambata R, Maleki-Toyserkani S, Yousuf M, Benjamin N, Webb AJ, Caulfield MJ, Hobbs AJ, and Ahluwalia A. Enhanced vasodilator activity of nitrite in hypertension: critical role for erythrocytic xanthine oxidoreductase and translational potential. Hypertension 61: 1091-1102, 2013.

59. Gielen S, Sandri M, Erbs S, and Adams V. Exerciseinduced modulation of endothelial nitric oxide production. Curr Pharm Biotechnol 12: 1375-1384, 2011.

60. Gladwin MT, Schechter A, Kim-Shapiro DB, Patel R, Hogg N, Shiva S, Cannon R, Kelm M, Wink D, Espey M, Oldfield E, Pluta R, Freeman B, Lancaster J, Feelisch M, and Lundberg JO. The emerging biology of the nitrite anion in signaling, blood flow and hypoxic nitric oxide homeostasis. Nat Chem Biol 1: 308-314, 2005.

61. Gladwin MT, Shelhamer JH, Schechter AN, Pease-Fye ME, Waclawiw MA, Panza JA, Ognibene FP, and Cannon Iii RO. Role of circulating nitrite and S-nitrosohemoglobin in the regulation of regional blood flow in humans. Proc Natl Acad Sci U S A 97: 11482-11487, 2000.

62. Gori T, Dragoni S, Lisi M, Di Stolfo G, Sonnati S, Fineschi M, and Parker JD. Conduit artery constriction mediated by low flow a novel noninvasive method for the assessment of vascular function. J Am Coll Cardiol 51: 1953-1958, 2008.

63. Griffith OW and Stuehr DJ. Nitric oxide synthases: properties and catalytic mechanism. Anпи Rev Physiol 57: 707-736, 1995.

64. Gudi S, Nolan JP, and Frangos JA. Modulation of GTPase activity of $\mathrm{G}$ proteins by fluid shear stress and phospholipid composition. Proc Natl Acad Sci U S A 95: 25152519, 1998.

65. Gullingsrud J and Schulten K. Lipid bilayer pressure profiles and mechanosensitive channel gating. Biophys $J$ 86: 3496-3509, 2004.

66. Hambrecht R, Adams V, Erbs S, Linke A, Krankel N, Shu Y, Baither Y, Gielen S, Thiele H, Gummert JF, Mohr FW, and Schuler G. Regular physical activity improves endothelial function in patients with coronary artery disease by increasing phosphorylation of endothelial nitric oxide synthase. Circulation 107: 3152-3158, 2003.

67. Hausenloy DJ, Candilio L, Evans R, Ariti C, Jenkins DP, Kolvekar S, Knight R, Kunst G, Laing C, Nicholas J, Pepper J, Robertson S, Xenou M, Clayton T, and Yellon DM. Remote ischemic preconditioning and outcomes of cardiac surgery. N Engl J Med 373: 1408-1417, 2015.

68. Hausenloy DJ and Yellon DM. Remote ischaemic preconditioning: underlying mechanisms and clinical application. Cardiovasc Res 79: 377-386, 2008.

69. Heinrich TA, da Silva RS, Miranda KM, Switzer CH, Wink DA, and Fukuto JM. Biological nitric oxide sig- nalling: chemistry and terminology. Br J Pharmacol 169: 1417-1429, 2013.

70. Heiss C, Lauer T, Dejam A, Kleinbongard P, Hamada S, Rassaf T, Matern S, Feelisch M, and Kelm M. Plasma nitroso compounds are decreased in patients with endothelial dysfunction. J Am Coll Cardiol 47: 573-579, 2006.

71. Heiss C, Meyer C, Totzeck M, Hendgen-Cotta UB, Heinen Y, Luedike P, Keymel S, Ayoub N, Lundberg JO, Weitzberg E, Kelm M, and Rassaf T. Dietary inorganic nitrate mobilizes circulating angiogenic cells. Free Radic Biol Med 52: 1767-1772, 2012.

72. Heiss C, Rodriguez-Mateos A, and Kelm M. Central role of eNOS in the maintenance of endothelial homeostasis. Antioxid Redox Signal 22: 1230-1242, 2015.

73. Helms C and Kim-Shapiro DB. Hemoglobin-mediated nitric oxide signaling. Free Radic Biol Med 61c: 464-472, 2013.

74. Herold S. The outer-sphere oxidation of nitrosyliron(II)hemoglobin by peroxynitrite leads to the release of nitrogen monoxide. Inorg Chem 43: 3783-3785, 2004.

75. Horn P, Cortese-Krott MM, Keymel S, Kumara I, Burghoff S, Schrader J, Kelm M, and Kleinbongard P. Nitric oxide influences red blood cell velocity independently of changes in the vascular tone. Free Radic Res 45: 653-661, 2011.

76. Hoyer J, Distler A, Haase W, and Gögelein H. Ca2+ influx through stretch-activated cation channels activates maxi $\mathrm{K}+$ channels in porcine endocardial endothelium. Proc Natl Acad Sci U S A 91: 2367-2371, 1994.

77. Ingber DE. Cellular tensegrity: defining new rules of biological design that govern the cytoskeleton. J Cell Sci 104 (Pt 3): 613-627, 1993.

78. Isbell TS, Sun CW, Wu LC, Teng X, Vitturi DA, Branch BG, Kevil CG, Peng N, Wyss JM, Ambalavanan N, Schwiebert L, Ren J, Pawlik KM, Renfrow MB, Patel RP, and Townes TM. SNO-hemoglobin is not essential for red blood cell-dependent hypoxic vasodilation. Nat Med 14: 773-777, 2008.

79. Iwakura A, Shastry S, Luedemann C, Hamada H, Kawamoto A, Kishore R, Zhu Y, Qin G, Silver M, Thorne T, Eaton L, Masuda H, Asahara T, and Losordo DW. Estradiol enhances recovery after myocardial infarction by augmenting incorporation of bone marrow-derived endothelial progenitor cells into sites of ischemia-induced neovascularization via endothelial nitric oxide synthasemediated activation of matrix metalloproteinase-9. Circulation 113: 1605-1614, 2006.

80. Jia L, Bonaventura C, Bonaventura J, and Stamler JS. Snitrosohaemoglobin: a dynamic activity of blood involved in vascular control. Nature 380: 221-226, 1996.

81. Jin Z-G, Ueba H, Tanimoto T, Lungu AO, Frame MD, and Berk BC. Ligand-independent activation of vascular endothelial growth factor receptor 2 by fluid shear stress regulates activation of endothelial nitric oxide synthase. Circ Res 93: 354-363, 2003.

82. Jin Z-G, Wong C, Wu J, and Berk BC. Flow shear stress stimulates Gab1 tyrosine phosphorylation to mediate protein kinase $\mathrm{B}$ and endothelial nitric-oxide synthase activation in endothelial cells. J Biol Chem 280: 1230512309, 2005.

83. Johnson BD, Mather KJ, and Wallace JP. Mechanotransduction of shear in the endothelium: basic studies and clinical implications. Vasc Med 16: 365-377, 2011.

84. Ju H, Venema VJ, Marrero MB, and Venema RC. Inhibitory interactions of the bradykinin B2 receptor with 
endothelial nitric-oxide synthase. J Biol Chem 273: 24025-24029, 1998.

85. Ju H, Zou R, Venema VJ, and Venema RC. Direct interaction of endothelial nitric-oxide synthase and caveolin-1 inhibits synthase activity. J Biol Chem 272: 18522-18525, 1997.

86. Keymel S, Sichwardt J, Balzer J, Stegemann E, Rassaf T, Kleinbongard P, Kelm M, Heiss C, and Lauer T. Characterization of the non-invasive assessment of the cutaneous microcirculation by laser Doppler perfusion scanner. Microcirculation 17: 358-366, 2010.

87. Kirby BS, Schwarzbaum PJ, Lazarowski ER, Dinenno FA, and McMahon TJ. Liberation of ATP secondary to hemolysis is not mutually exclusive of regulated export. Blood 125: 1844-1845, 2015.

88. Kleinbongard P, Schulz R, Rassaf T, Lauer T, Dejam A, Jax T, Kumara I, Gharini P, Kabanova S, Ozüyaman B, Schnürch H-G, Gödecke A, Weber A-A, Robenek M, Robenek H, Bloch W, Rösen P, and Kelm M. Red blood cells express a functional endothelial nitric oxide synthase. Blood 107: 2943-2951, 2006.

89. Kojda $G$ and Hambrecht R. Molecular mechanisms of vascular adaptations to exercise. Physical activity as an effective antioxidant therapy? Cardiovasc Res 67: 187197, 2005.

90. Kristiansen SB, Henning O, Kharbanda RK, NielsenKudsk JE, Schmidt MR, Redington AN, Nielsen TT, and Botker HE. Remote preconditioning reduces ischemic injury in the explanted heart by a KATP channeldependent mechanism. Am J Physiol Heart Circ Physiol 288: H1252-H1256, 2005.

91. Laufs U, Werner N, Link A, Endres M, Wassmann S, Jurgens K, Miche E, Bohm M, and Nickenig G. Physical training increases endothelial progenitor cells, inhibits neointima formation, and enhances angiogenesis. Circulation 109: 220-226, 2004.

92. Lee AG. How lipids affect the activities of integral membrane proteins. Biochim Biophys Acta 1666: 62-87, 2004.

93. Lenk K, Uhlemann M, Schuler G, and Adams V. Role of endothelial progenitor cells in the beneficial effects of physical exercise on atherosclerosis and coronary artery disease. J Appl Physiol (1985) 111: 321-328, 2011.

94. Li Z, Delaney MK, O’Brien KA, and Du X. Signaling during platelet adhesion and activation. Arterioscler Thromb Vasc Biol 30: 2341-2349, 2010.

95. Lieu DK, Pappone PA, and Barakat AI. Differential membrane potential and ion current responses to different types of shear stress in vascular endothelial cells. Am J Physiol Cell Physiol 286: C1367-C1375, 2004.

96. Liu C, Wajih N, Liu X, Basu S, Janes J, Marvel M, Keggi C, Helms CC, Lee AN, Belanger AM, Diz DI, Laurienti PJ, Caudell DL, Wang J, Gladwin MT, and Kim-Shapiro DB. Mechanisms of human erythrocytic bioactivation of nitrite. J Biol Chem 290: 1281-1294, 2015.

97. Liu H-B, Zhang J, Xin S-Y, Liu C, Wang C-Y, Zhao D, and Zhang Z-R. Mechanosensitive properties in the endothelium and their roles in the regulation of endothelial function. J Cardiovasc Pharmacol 61: 461-470, 2013.

98. Liu X, Miller MJ, Joshi MS, Sadowska-Krowicka H, Clark DA, and Lancaster JR, Jr. Diffusion-limited reaction of free nitric oxide with erythrocytes. J Biol Chem 273: 18709-18713, 1998.
99. Lohman AW, Billaud M, and Isakson BE. Mechanisms of ATP release and signalling in the blood vessel wall. Cardiovasc Res 95: 269-280, 2012.

100. Loufrani L, Retailleau K, Bocquet A, Dumont O, Danker $\mathrm{K}$, Louis H, Lacolley $\mathrm{P}$, and Henrion D. Key role of alpha(1)beta(1)-integrin in the activation of PI3-kinaseAkt by flow (shear stress) in resistance arteries. Am J Physiol Heart Circ Physiol 294: H1906-H1913, 2008.

101. Lundberg JO, Gladwin MT, Ahluwalia A, Benjamin N, Bryan NS, Butler A, Cabrales P, Fago A, Feelisch M, Ford PC, Freeman BA, Frenneaux M, Friedman J, Kelm M, Kevil CG, Kim-Shapiro DB, Kozlov AV, Lancaster JR, Jr., Lefer DJ, McColl K, McCurry K, Patel RP, Petersson J, Rassaf T, Reutov VP, Richter-Addo GB, Schechter A, Shiva S, Tsuchiya K, van Faassen EE, Webb AJ, Zuckerbraun BS, Zweier JL, and Weitzberg E. Nitrate and nitrite in biology, nutrition and therapeutics. Nat Chem Biol 5: 865-869, 2009.

102. Mergia E, Friebe A, Dangel O, Russwurm M, Koesling D. Spare guanylyl cyclase NO receptors ensure high NO sensitivity in the vascular system. J Clin Invest 116: 17311737, 2006

103. Merx MW, Gorressen S, van de Sandt AM, Cortese-Krott MM, Ohlig J, Stern M, Rassaf T, Godecke A, Gladwin MT, and Kelm M. Depletion of circulating blood NOS3 increases severity of myocardial infarction and left ventricular dysfunction. Basic Res Cardiol 109: 398, 2014.

104. Moncada S, Palmer RM, and Higgs EA. Nitric oxide: physiology, pathophysiology, and pharmacology. Pharmacol Rev 43: 109-142, 1991.

105. Murry CE, Jennings RB, and Reimer KA. Preconditioning with ischemia: a delay of lethal cell injury in ischemic myocardium. Circulation 74: 1124-1136, 1986.

106. Nakache $M$ and Gaub HE. Hydrodynamic hyperpolarization of endothelial cells. Proc Natl Acad Sci U S A 85: 1841-1843, 1988.

107. Olesen SP, Clapham DE, and Davies PF. Haemodynamic shear stress activates a $\mathrm{K}+$ current in vascular endothelial cells. Nature 331: 168-170, 1988.

108. Park JW, Piknova B, Huang PL, Noguchi CT, and Schechter AN. Effect of blood nitrite and nitrate levels on murine platelet function. PLoS One 8: e55699, 2013.

109. Pawloski JR, Hess DT, and Stamler JS. Export by red blood cells of nitric oxide bioactivity. Nature 409: 622626, 2001.

110. Perk J, De Backer G, Gohlke H, Graham I, Reiner Z, Verschuren M, Albus C, Benlian P, Boysen G, Cifkova R, Deaton C, Ebrahim S, Fisher M, Germano G, Hobbs R, Hoes A, Karadeniz S, Mezzani A, Prescott E, Ryden L, Scherer M, Syvänne M, Scholte op Reimer WJM, Vrints C, Wood D, Zamorano JL, Zannad F; and European Association for Cardiovascular Prevention \& Rehabilitation (EACPR); ESC Committee for Practice Guidelines (CPG). European Guidelines on cardiovascular disease prevention in clinical practice (version 2012). The Fifth Joint Task Force of the European Society of Cardiology and Other Societies on Cardiovascular Disease Prevention in Clinical Practice (constituted by representatives of nine societies and by invited experts). Eur Heart J 33: 1635-1701, 2012.

111. Prior BM, Yang HT, and Terjung RL. What makes vessels grow with exercise training? J Appl Physiol 97: 11191128, 2004.

112. Przyklenk K, Bauer B, Ovize M, Kloner RA, and Whittaker P. Regional ischemic 'preconditioning' protects re- 
mote virgin myocardium from subsequent sustained coronary occlusion. Circulation 87: 893-899, 1993.

113. Qiu Y, Ciciliano J, Myers DR, Tran R, and Lam WA. Platelets and physics: how platelets "feel" and respond to their mechanical microenvironment. Blood Rev 29: 377-386, 2015.

114. Quillon A, Fromy B, and Debret R. Endothelium microenvironment sensing leading to nitric oxide mediated vasodilation: a review of nervous and biomechanical signals. Nitric Oxide 45: 20-26, 2015.

115. Rapoport RM, Draznin MB, and Murad F. Endotheliumdependent relaxation in rat aorta may be mediated through cyclic GMP-dependent protein phosphorylation. Nature 306: 174-176, 1983.

116. Rassaf T, Bryan NS, Maloney RE, Specian V, Kelm M, Kalyanaraman B, Rodriguez J, and Feelisch M. NO adducts in mammalian red blood cells: too much or too little? Nat Med 9: 481-482, 2003.

117. Rassaf T, Totzeck M, Hendgen-Cotta UB, Shiva S, Heusch G, and Kelm M. Circulating nitrite contributes to cardioprotection by remote ischemic preconditioning. Circ Res 114: 1601-1610, 2014.

118. Ravi K, Brennan LA, Levic S, Ross PA, and Black SM. Snitrosylation of endothelial nitric oxide synthase is associated with monomerization and decreased enzyme activity. Proc Natl Acad Sci U S A 101: 2619-2624, 2004.

119. Reitsma S, Slaaf DW, Vink H, van Zandvoort MA, and oude Egbrink MG. The endothelial glycocalyx: composition, functions, and visualization. Pflugers Arch 454: 345-359, 2007.

120. Rodriguez J, Maloney RE, Rassaf T, Bryan NS, and Feelisch M. Chemical nature of nitric oxide storage forms in rat vascular tissue. Proc Natl Acad Sci U S A 100: 336341, 2003.

121. Rosendorff C, Black HR, Cannon CP, Gersh BJ, Gore J, Izzo JL, Kaplan NM, O'Connor CM, O'Gara PT, Oparil $\mathrm{S}$; American Heart Association Council for High Blood Pressure Research; American Heart Association Council on Clinical Cardiology; American Heart Association Council on Epidemiology and Prevention. Treatment of hypertension in the prevention and management of ischemic heart disease: a scientific statement from the American Heart Association Council for High Blood Pressure Research and the Councils on Clinical Cardiology and Epidemiology and Prevention. Circulation 115: 2761-2788, 2007.

122. Rukoyatkina N, Walter U, Friebe A, and Gambaryan S. Differentiation of cGMP-dependent and-independent nitric oxide effects on platelet apoptosis and reactive oxygen species production using platelets lacking soluble guanylyl cyclase. Thromb Haemost 106: 922-933, 2011.

123. Russwurm M, Russwurm C, Koesling D, Mergia E. NO/ cGMP: The Past, the Present, and the Future. In: Guanylate Cyclase and Cyclic GMP. edited by Krieg T, Lukowski R. Humana Press; 2013. pp. 1-16

124. Salgado MT, Cao Z, Nagababu E, Mohanty JG, and Rifkind JM. Red blood cell membrane-facilitated release of nitrite-derived nitric oxide bioactivity. Biochemistry 54: 6712-6723, 2015.

125. Schuler D, Sansone R, Freudenberger T, Rodriguez-Mateos A, Weber G, Momma TY, Goy C, Altschmied J, Haendeler J, Fischer JW, Kelm M, and Heiss C. Measurement of endothelium-dependent vasodilation in mice-brief report. Arterioscler Thromb Vasc Biol 34: 2651-2657, 2014.
126. Schuler G, Adams V, and Goto Y. Role of exercise in the prevention of cardiovascular disease: results, mechanisms, and new perspectives. Eur Heart J 34: 1790-1799, 2013.

127. Schwartz MA. Integrin signaling revisited. Trends Cell Biol 11: 466-470, 2001.

128. Sessa WC. eNOS at a glance. J Cell Sci 117: 2427-2429, 2004.

129. Sessa WC, Barber CM, and Lynch KR. Mutation of Nmyristoylation site converts endothelial cell nitric oxide synthase from a membrane to a cytosolic protein. Circ Res 72: 921-924, 1993.

130. Siegel-Axel DI and Gawaz M. Platelets and endothelial cells. Semin Thromb Hemost 33: 128-135, 2007.

131. Sikora J, Orlov SN, Furuya K, and Grygorczyk R. Hemolysis is a primary ATP-release mechanism in human erythrocytes. Blood 124: 2150-2157, 2014.

132. Singleton PA and Bourguignon LYW. CD44 interaction with ankyrin and IP3 receptor in lipid rafts promotes hyaluronan-mediated $\mathrm{Ca} 2+$ signaling leading to nitric oxide production and endothelial cell adhesion and proliferation. Exp Cell Res 295: 102-118, 2004.

133. Straub AC, Lohman AW, Billaud M, Johnstone SR, Dwyer ST, Lee MY, Bortz PS, Best AK, Columbus L, Gaston B, and Isakson BE. Endothelial cell expression of haemoglobin $\alpha$ regulates nitric oxide signalling. Nature 491: 473-477, 2012.

134. Suvorava T, Kumpf S, Rauch BH, Dao VT, Adams V, and Kojda G. Hydrogen peroxide inhibits exercise-induced increase of circulating stem cells with endothelial progenitor capacity. Free Radic Res 44: 199-207, 2010.

135. Suvorava T, Lauer N, and Kojda G. Physical inactivity causes endothelial dysfunction in healthy young mice. $J$ Am Coll Cardiol 44: 1320-1327, 2004.

136. Tai L-K, Okuda M, Abe J-I, Yan C, and Berk BC. Fluid shear stress activates proline-rich tyrosine kinase via reactive oxygen species-dependent pathway. Arterioscler Thromb Vasc Biol 22: 1790-1796, 2002.

137. Totzeck M, Hendgen-Cotta UB, Luedike P, Berenbrink M, Klare JP, Steinhoff HJ, Semmler D, Shiva S, Williams D, Kipar A, Gladwin MT, Schrader J, Kelm M, Cossins $\mathrm{AR}$, and Rassaf T. Nitrite regulates hypoxic vasodilation via myoglobin-dependent nitric oxide generation. Circulation 126: 325-334, 2012.

138. Tsuda K, Kimura K, Nishio I, and Masuyama Y. Nitric oxide improves membrane fluidity of erythrocytes in essential hypertension: an electron paramagnetic resonance investigation. Biochem Biophys Res Commun 275: 946954, 2000.

139. Tzima E, Irani-Tehrani M, Kiosses WB, Dejana E, Schultz DA, Engelhardt B, Cao G, DeLisser H, and Schwartz MA. A mechanosensory complex that mediates the endothelial cell response to fluid shear stress. Nature 437: 426-431, 2005.

140. van Duinen V, Trietsch SJ, Joore J, Vulto P, and Hankemeier T. Microfluidic 3D cell culture: from tools to tissue models. Curr Opin Biotechnol 35: 118-126, 2015.

141. Waid DK, Chell M, and El-Fakahany EE. M(2) and M(4) muscarinic receptor subtypes couple to activation of endothelial nitric oxide synthase. Pharmacology 61: 37-42, 2000.

142. Walter U and Gambaryan S. Roles of cGMP/cGMPdependent protein kinase in platelet activation. Blood 104: 2609, 2004. 
143. Wan J, Forsyth AM, and Stone HA. Red blood cell dynamics: from cell deformation to ATP release. Integr Biol (Camb) 3: 972-981, 2011.

144. Wan J, Ristenpart WD, and Stone HA. Dynamics of shearinduced ATP release from red blood cells. Proc Natl Acad Sci U S A 105: 16432-16437, 2008.

145. Wang N, Tytell JD, and Ingber DE. Mechanotransduction at a distance: mechanically coupling the extracellular matrix with the nucleus. Nat Rev Mol Cell Biol 10: 75-82, 2009.

146. Wang X, Bryan NS, MacArthur PH, Rodriguez J, Gladwin MT, and Feelisch M. Measurement of nitric oxide levels in the red cell: validation of tri-iodide-based chemiluminescence with acid-sulfanilamide pretreatment. $J$ Biol Chem 281: 26994-27002, 2006.

147. Wasserman SM, Mehraban F, Komuves LG, Yang RB, Tomlinson JE, Zhang Y, Spriggs F, and Topper JN. Gene expression profile of human endothelial cells exposed to sustained fluid shear stress. Physiol Genomics 12: 13-23, 2002.

148. Webb A, Milsom A, Rathod K, Chu W, Qureshi S, Lovell M, Lecomte F, Perrett D, Raimondo C, Khoshbin E, Ahmed Z, Uppal R, Benjamin N, Hobbs A, and Ahluwalia A. Mechanisms underlying erythrocyte and endothelial nitrite reduction to nitric oxide in hypoxia: role for xanthine oxidoreductase and endothelial nitric oxide synthase. Circ Res 103: 957-964, 2008.

149. Wedel B, Harteneck C, Foerster J, Friebe A, Schultz G, and Koesling D. Functional domains of soluble guanylyl cyclase. J Biol Chem 270: 24871-24875, 1995.

150. Winger JA, Derbyshire ER, and Marletta MA. Dissociation of nitric oxide from soluble guanylate cyclase and heme-nitric oxide/oxygen binding domain constructs. $J$ Biol Chem 282: 897-907, 2007.

151. Wisløff U, Støylen A, Loennechen JP, Bruvold M, Rognmo Ø, Haram PM, Tjønna AE, Helgerud J, Slørdahl SA, Lee SJ, Videm V, Bye A, Smith GL, Najjar SM, Ellingsen $\varnothing$, and Skjaerpe T. Superior cardiovascular effect of aerobic interval training versus moderate continuous training in heart failure patients: a randomized study. Circulation 115: 3086-3094, 2007.

152. Wolfrum S, Schneider K, Heidbreder M, Nienstedt J, Dominiak P, and Dendorfer A. Remote preconditioning protects the heart by activating myocardial PKCepsilonisoform. Cardiovasc Res 55: 583-589, 2002.

153. Wood KC, Cortese-Krott MM, Kovacic JC, Noguchi A, Liu VB, Wang X, Raghavachari N, Boehm M, Kato GJ, Kelm M, and Gladwin MT. Circulating blood endothelial nitric oxide synthase contributes to the regulation of systemic blood pressure and nitrite homeostasis. Arterioscler Thromb Vasc Biol 33: 1861-1871, 2013.

154. Yamamoto K, Korenaga R, Kamiya A, Qi Z, Sokabe M, and Ando J. P2X(4) receptors mediate ATP-induced calcium influx in human vascular endothelial cells. Am J Physiol Heart Circ Physiol 279: H285-H292, 2000.

155. Yang BC, Nichols WW, and Mehta JL. Cardioprotective effects of red blood cells on ischemia and reperfusion injury in isolated rat heart: release of nitric oxide as a potential mechanism. J Cardiovasc Pharmacol Ther 1: 297-305, 1996.

156. Yang J, Gonon AT, Sjoquist PO, Lundberg JO, and Pernow J. Arginase regulates red blood cell nitric oxide synthase and export of cardioprotective nitric oxide bio- activity. Proc Natl Acad Sci U S A 110: 15049-15054, 2013.

157. Yao Y, Rabodzey A, and Dewey CF, Jr. Glycocalyx modulates the motility and proliferative response of vascular endothelium to fluid shear stress. Am J Physiol Heart Circ Physiol 293: H1023-H1030, 2007.

158. Yin G, Yan C, and Berk BC. Angiotensin II signaling pathways mediated by tyrosine kinases. Int J Biochem Cell Biol 35: 780-783, 2003.

159. Yu J, Bergaya S, Murata T, Alp IF, Bauer MP, Lin MI, Drab M, Kurzchalia TV, Stan RV, and Sessa WC. Direct evidence for the role of caveolin-1 and caveolae in mechanotransduction and remodeling of blood vessels. J Clin Invest 116: 1284-1291, 2006.

160. Zhang G, Xiang B, Dong A, Skoda RC, Daugherty A, Smyth SS, Du X, and Li Z. Biphasic roles for soluble guanylyl cyclase (sGC) in platelet activation. Blood 118: 3670-3679, 2011.

161. Zhang R, Hess DT, Qian Z, Hausladen A, Fonseca F, Chaube R, Reynolds JD, and Stamler JS. Hemoglobin betaCys93 is essential for cardiovascular function and integrated response to hypoxia. Proc Natl Acad Sci U S A 112: 6425-6430, 2015.

Address correspondence to: Prof. Dr. Miriam M. Cortese-Krott Cardiovascular Research Laboratory

Division of Cardiology, Pneumology and Angiology Medical Faculty Heinrich Heine University of Düsseldorf Moorenstrasse 5 Düssledorf 40225 Germany

E-mail: miriam.cortese@uni-duesseldorf.de

Date of first submission to ARS Central, November 1, 2016; date of final revised submission, December 4, 2016; date of acceptance, December 7, 2016.

$\begin{aligned} & \text { Abbreviations Used } \\ & \mathrm{Ach}= \text { acetylcholine } \\ & \mathrm{AE} 1=\text { anion exchanger } 1 \\ & \mathrm{AP}-1=\text { activator protein } 1 \\ & \mathrm{ATP}=\text { adenosine triphosphate } \\ & \mathrm{B} 2 \text { receptor }=\text { bradykinin } 2 \text { receptor } \\ & \mathrm{BK}=\text { bradykinin } \\ & \mathrm{CaM}=\text { calmodulin } \\ & \mathrm{CaMKII}=\text { calcium/calmodulin-dependent protein } \\ & \text { kinase II } \\ & \mathrm{cGMP}=3^{\prime}, 5^{\prime} \text {-cyclic guanosine monophosphate } \\ & \text { deoxyxHb }=\text { deoxygenated hemoglobin } \\ & \mathrm{EC}=\text { endothelial cell } \\ & \mathrm{Egr}-1=\text { early growth response protein } 1 \\ & \mathrm{eNOS}=\text { endothelial nitric oxide synthase } \\ & \mathrm{EPC}=\text { endothelial progenitor cell } \\ & \mathrm{ESI}=\text { electrospray ionization } \\ & \mathrm{FMD}=\text { flow-mediated dilation } \\ & \mathrm{GATA6}=\text { GATA-binding protein } 6\end{aligned}$




$\begin{aligned} & \text { Abbreviations Used (Cont.) } \\ & \text { GPCR }=\text { G protein-coupled receptor } \\ & \mathrm{GTP}=\text { guanosine-5' triphosphate } \\ & \mathrm{HbSNO}=\text { S-nitrosohemoglobin } \\ & \mathrm{HDL}=\text { high-density lipoprotein } \\ & \mathrm{HPLC}=\text { high-performance liquid } \\ & \text { chromatography } \\ & \mathrm{KCa}=\text { calcium-activated potassium channel } \\ & \mathrm{KH}-\mathrm{RBC}=\text { Krebs-Henseleit buffer containing } \\ & \text { Kir }=\text { inward-rect cellsying potassium channel } \\ & \mathrm{KLF} 2=\text { Krüppel-like factor } 2 \\ & \mathrm{KO}=\text { knockout } \\ & \mathrm{L}-\mathrm{Arg}=\mathrm{L}-\text { arginine } \\ & \mathrm{LC}=\text { liquid chromatography } \\ & \mathrm{L}-\mathrm{NAME}=1-\mathrm{NG}-\mathrm{nitroarginine} \text { methylester } \\ & \mathrm{L}-\mathrm{NIO}=\text { N5-(1-iminoethyl-1-ornithine }) \\ & \mathrm{miRNA}=\text { microRNA } \\ & \mathrm{MLC}=\text { myosin light chain } \\ & \mathrm{MLCK}=\text { myosin light chain kinase } \\ & \mathrm{mRNA}=\text { messenger RNA } \\ & \mathrm{MS}=\text { mass spectrometer }\end{aligned}$

$\mathrm{NF}-\mathrm{kB}=$ nuclear factor kappa-light-chainenhancer of activated B cells

$\mathrm{NO}=$ nitric oxide

PECAM- $1=$ platelet endothelial cell adhesion molecule-1

$\mathrm{PGF}=$ placental growth factor

$\mathrm{PI}_{3} \mathrm{~K}=$ phosphoinositide 3-kinase

$\mathrm{PKA}=$ protein kinase $\mathrm{A}$

$\mathrm{PKC}=$ protein kinase $\mathrm{C}$

$\mathrm{PKG}=$ protein kinase $\mathrm{G}$

PYK2 = proline-rich tyrosine kinase 2

$\mathrm{RBC}=$ red blood cell

$\mathrm{sGC}=$ soluble guanylate cyclase

$\mathrm{SMC}=$ smooth muscle cell

$\mathrm{SP}-1=$ specificity protein 1

$\mathrm{TF}=$ transcriptional factor

$\mathrm{TK}=$ tyrosine kinase

$\mathrm{TKR}=$ tyrosine kinase receptor

TRPV $4=$ transient receptor potential vanilloid 4

VGEFR2 $=$ vascular endothelial growth factor receptor 2

$\mathrm{VSMC}=$ vascular smooth muscle cell 